\title{
Tetrathiafulvalene - a redox-switchable building block to control motion in mechanically interlocked molecules
}

\author{
Hendrik V. Schröder and Christoph A. Schalley ${ }^{*}$
}

\begin{tabular}{|c|c|}
\hline Review & Open Access \\
\hline Address: & Beilstein J. Org. Chem. 2018, 14, 2163-2185. \\
\hline Institut für Chemie und Biochemie, Organische Chemie, Freie & doi:10.3762/bjoc.14.190 \\
\hline \multicolumn{2}{|l|}{ Universität Berlin, Takustraße 3, 14195 Berlin, Germany } \\
\hline & Received: 13 April 2018 \\
\hline Email: & Accepted: 01 August 2018 \\
\hline Christoph A. Schalley ${ }^{*}$ - c.schalley@fu-berlin.de & Published: 20 August 2018 \\
\hline${ }^{*}$ Corresponding author & $\begin{array}{l}\text { This article is part of the thematic issue "Macrocyclic and supramolecular } \\
\text { chemistry". }\end{array}$ \\
\hline \multirow{3}{*}{$\begin{array}{l}\text { Keywords: } \\
\text { artificial molecular machines; mechanically interlocked molecules; } \\
\text { molecular switches; supramolecular chemistry; tetrathiafulvalene }\end{array}$} & \multirow[b]{2}{*}{ Guest Editor: M.-X. Wang } \\
\hline & \\
\hline & $\begin{array}{l}\text { (c) } 2018 \text { Schröder and Schalley; licensee Beilstein-Institut. } \\
\text { License and terms: see end of document. }\end{array}$ \\
\hline
\end{tabular}

\begin{abstract}
With the rise of artificial molecular machines, control of motion on the nanoscale has become a major contemporary research challenge. Tetrathiafulvalenes (TTFs) are one of the most versatile and widely used molecular redox switches to generate and control molecular motion. TTF can easily be implemented as functional unit into molecular and supramolecular structures and can be reversibly oxidized to a stable radical cation or dication. For over 20 years, TTFs have been key building blocks for the construction of redox-switchable mechanically interlocked molecules (MIMs) and their electrochemical operation has been thoroughly investigated. In this review, we provide an introduction into the field of TTF-based MIMs and their applications. A brief historical overview and a selection of important examples from the past until now are given. Furthermore, we will highlight our latest research on TTF-based rotaxanes.
\end{abstract}

\section{Introduction}

Undoubtedly, the exploration of nature's molecular machines in the last century led to a paradigm change of how we think about working and organization processes on the molecular level [1-3]. Inspired by the way how energy and concentration gradients control repetitive motions of these biological nanomachines, researchers have been seeking for synthetic analogues, i.e., artificial molecular machines (AMMs), with the ultimate goal to convert energy into directional mechanical motion on the nanoscale [4-6]. The field of AMMs beautifully coalesces the desire of reproducing the versatile functions of nature's biomachinery and the miniaturization of macroscopic technical devices made by man. Although the field of AMMs is relatively young, the Nobel Prize in 2016 for Jean-Pierre Sauvage [7], Sir J. Fraser Stoddart [8], and Bernard L. Feringa [9] "for the 
design and synthesis of molecular machines" is an outstanding appreciation of the public and scientific community.

Mechanically interlocked molecules (MIMs) such as rotaxanes [10] or catenanes [11] are ideally suited for the construction of AMMs. In comparison to covalently linked molecules, the mechanical bond provides cohesive supramolecular assemblies with unique properties and a high flexibility and mobility of the subcomponents in a small molecular space. To control molecular motion, one of the most important construction principles to transform a simple MIM into an AMM is to implement a switching unit into the molecular framework, which is reversibly addressable by external stimuli $[12,13]$. A variety of different stimuli to control MIMs has been reported ranging, for example, from physical stimuli such as electrons, light, temperature, pressure, or magnetism to chemical stimuli such as acids/ bases, ions, additives, or solvent changes [14]. However, the latter class of stimuli bears the disadvantage to produce chemical "waste" which creates the challenging task to constantly add and remove material to and from the system, if a repetitive operation is desired. Therefore, a "clean" stimulus is often preferred.

One of the most frequently used and thoroughly characterized "clean" switches to control molecular motion of MIMs is tetrathiafulvalene (TTF, 1) and its derivatives (Figure 1). TTF is a redox-switchable organosulfur compound, which exhibits ideal properties for the electrochemical operation of MIMs. Several excellent reviews on the use of TTF in other supramolecular systems such as macrocycles, cages, and receptor molecules are already available [15-21]. In this review, motifs of construction and working principles of TTF-based MIMs in the past and current literature are summarized and milestones of their development are discussed. In the first part, we will briefly describe how TTF evolved into a key building block for switchable supramolecular architectures and which synthetic breakthroughs enabled this development. We also aim for a tutorial introduction to readers new to the field of TTF-switchable MIMs.

\section{Review}

\section{Tetrathiafulvalene - an (almost) perfect molecular switch}

Whereas inorganic chemists are used to commonly handle metal-based compounds in different oxidation states, only a small selection of organic molecules [22] can be reversibly oxidized or reduced without chemical side reactions or decomposition. TTF is perhaps one of the most popular examples and exists as a classical Weitz type redox system [22] in three different stable oxidation states. The stability of TTF, both in solution and in the solid state [23], makes it an ideal molecular switch.

A first one-electron oxidation [23] converts neutral TTF (1) into the radical-cationic species $\mathbf{1}^{\bullet+}$ (Figure 1). The TTF radical cation is one of the rare organic radicals that are long-term stable and even isolable. A second oxidation step yields the dication $\mathbf{1}^{2+}$. Both redox-transitions are fully reversible and have surprisingly low oxidation potentials $(0.37$ and $0.74 \mathrm{~V}$ vs $\mathrm{Ag} / \mathrm{AgCl}$ in $\mathrm{CH}_{3} \mathrm{CN}$ ) [24], which enable an easily achievable electrochemical switching under ambient conditions. The stability of all oxidation states - even in the presence of air and moisture - is crucial for the efficient operation and characterization of TTF-based MIMs on a suitable laboratory timescale.

The observed stability of the two oxidation states can be explained by the stepwise aromatization of the TTF system. In the neutral state, TTF consists of two pro-aromatic 1,3-dithiolylidene rings which are connected by a $\mathrm{C}=\mathrm{C}$ double bond. The first oxidation converts one ring into an aromatic $6 \pi$-electron system, which is further stabilized by a mixed-valence resonance structure. The second oxidation yields two aromatic 1,3dithiolium cations $(2 \times 6 \pi$ electrons $)$ which are connected by a $\mathrm{C}-\mathrm{C}$ single bond.

The change of the electronic structure is also accompanied by conformational changes $[25,26]$ of the TTF skeleton. Neutral TTF has a boat-shaped structure with $C_{2 v}$ symmetry. In the

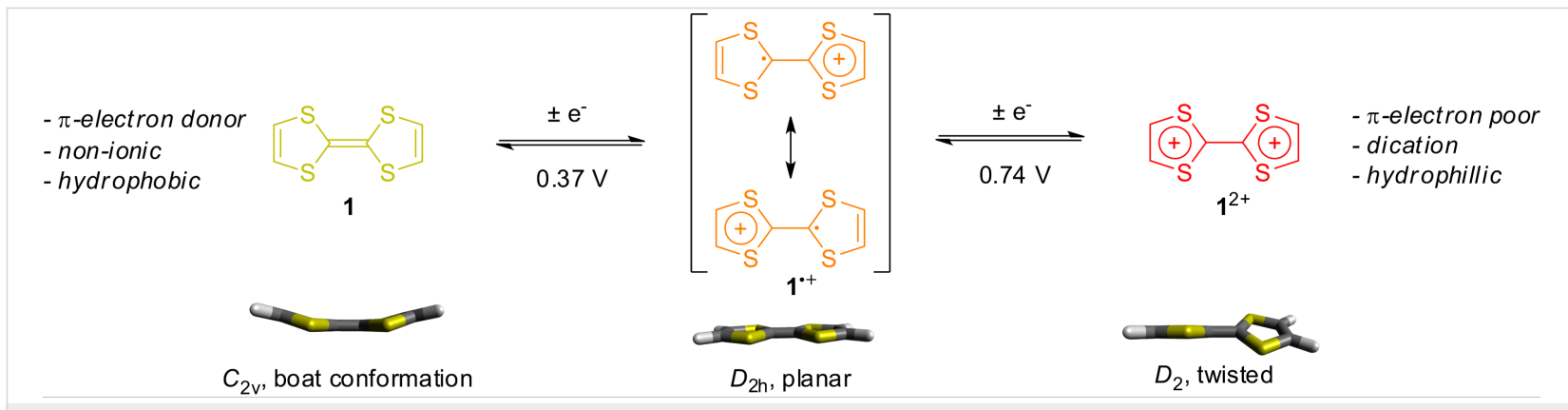

Figure 1: The two one-electron oxidation reactions of tetrathiafulvalene $(T T F, 1)$ and the corresponding property changes. 
radical-cation state, $\mathrm{TTF}^{\bullet+}$ planarizes into a $D_{2 h}$-symmetric structure due to its partial aromatization. This property change is widely used to induce cofacial intermolecular stacking interactions. Finally, the $\mathrm{TTF}^{2+}$ dication adopts a twisted conformation with $D_{2}$ symmetry.

In the neutral state, TTF is a strong $\pi$-donor molecule, a property which is used in a plethora of charge-transfer materials and molecules [27]. In supramolecular chemistry [28] and for the construction of MIMs [29], the good $\pi$-donor properties of TTF are frequently used to template donor-acceptor complexes with $\pi$-electron deficient macrocycles. If TTF undergoes oxidation, the $\pi$-donating effect decreases, whereas the $\mathrm{TTF}^{2+}$ dication can be considered as a $\pi$-electron-poor molecule.

The electrochemical switching of a TTF unit and the change of electronic or conformational properties not necessarily results in a mechanical motion of a MIM. A prerequisite is that at least one of the above-mentioned properties of TTF is interacting with other parts of the MIM. If this property is changed, the previous conformation of the MIM might become unstable and initiates a molecular motion. This simple principle of bistability has been used to create a variety of different switchable TTFbased supramolecular architectures with many versatile applications.

On the macroscopic as well as on the molecular level, even the most efficient switch is useless, if no observable output is generated which helps to detect the switching process [30]. A simple "read out" is provided by the optical properties of TTF in its different switching states. For example, UV-vis spectra of the TTF derivative $\mathbf{2}$ in the neutral, radical-cation, and dication state are shown in Figure 2. The spectrum of $\mathbf{2}$ shows only weak absorption above $350 \mathrm{~nm}$ which results in a pale yellow solution. The lowest-energy band is the HOMO $\rightarrow$ LUMO transition of the molecule. The radical-cation $\mathbf{2}^{\bullet+}$ exhibits two strong absorption bands $(\approx 450$ and $800 \mathrm{~nm}$ ), which yield an orangebrown solution. Initially, the low-energy band of $\mathbf{2}^{\bullet+}$ between $600-1000 \mathrm{~nm}$ was interpreted as a signature for an unusually stable TTF dimer [31]. However, later investigations showed that this band is an intrinsic SOMO- $1 \rightarrow$ SOMO transition in the $\mathbf{2}^{\bullet+}$ radical cation [32]. The dication $\mathbf{2}^{2+}$ shows a strong band at $\approx 700 \mathrm{~nm}$ which results in a deep-blue solution. These strong color changes differ for differently substituted TTF derivatives and make it very easy to follow the electrochemical switching of TTF, even with the naked eye.

Other optical properties which are very helpful for observing the molecular switching in MIMs are charge-transfer bands. The $\pi$-donor TTF can form donor-acceptor complexes with $\pi$-electron-poor aromatic compounds often indicated by a green

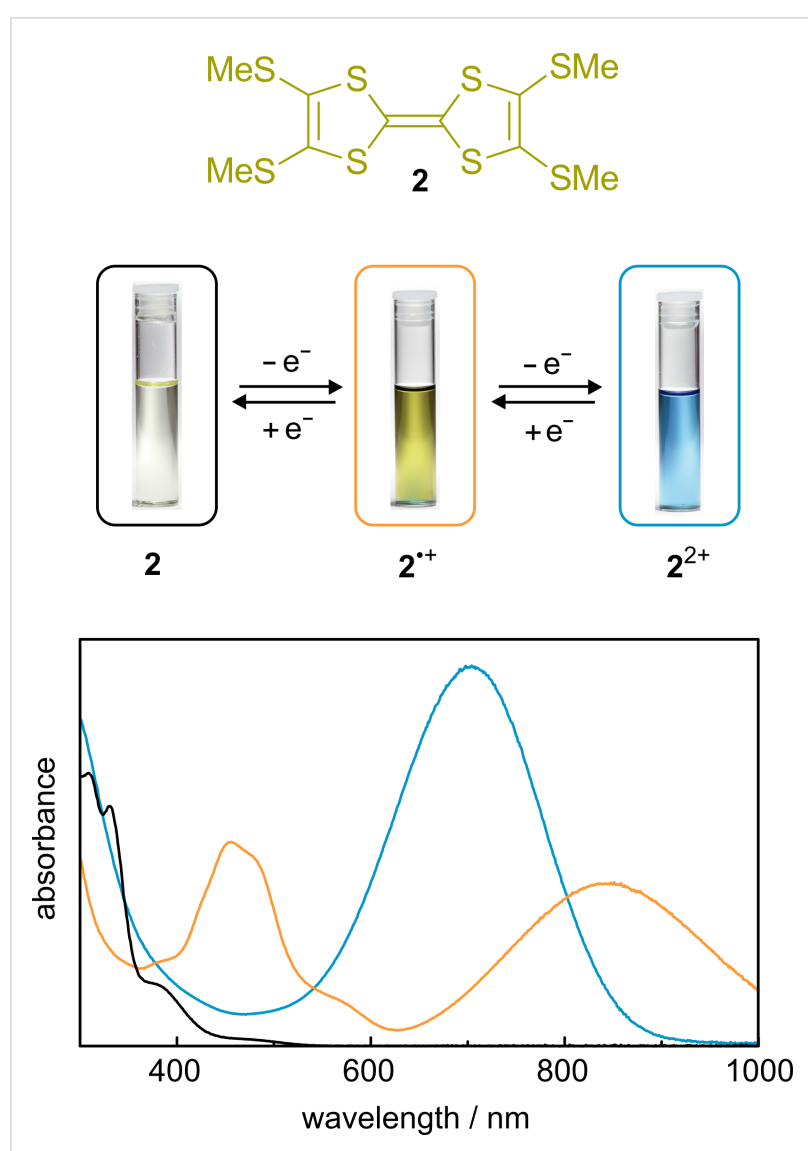

Figure 2: UV-vis spectra and photographs of TTF 2 in its three stable oxidation states (black line $=\mathbf{2}$, orange line $=\mathbf{2}^{\bullet+}$, blue line $=\mathbf{2}^{2+}$ ).

color of the solution [33]. Therefore, the assembly and disassembly of these complexes in solution can be easily traced by the emergence and fading of these characteristic charge-transfer bands.

Another outstanding feature of TTFs is that their radical cations can reversibly form cofacial dimers (Figure 3) [34-36]. The two monomers $\mathbf{1}$ and $\mathbf{1}^{\bullet+}$ spontaneously self-assemble into a so-called mixed-valence dimer $\left(\mathbf{1}_{2}\right)^{\bullet+}$. A mixed-valence dimer can be identified by splitting of the first TTF oxidation potential into two distinguishable waves. This change in redox behavior can be followed by electrochemical methods such as cyclic voltammetry. Another indication for a mixed-valence dimer interaction can be an emergent low-energy absorption band, usually in the NIR region. Both monomers show usually no absorption in this region.

The radical-cation dimer $\left(\mathbf{1}^{\bullet+}\right)_{2}$ instead forms from two $\mathbf{1}^{\bullet+}$ radical cations and exhibits a very unusual binding situation. Whereas both monomers are paramagnetic radicals, the resulting dimer has a diamagnetic character due to radical pairing. Although the distance of $\approx 3.5 \AA$ between the two $1^{\bullet+}$ mole- 


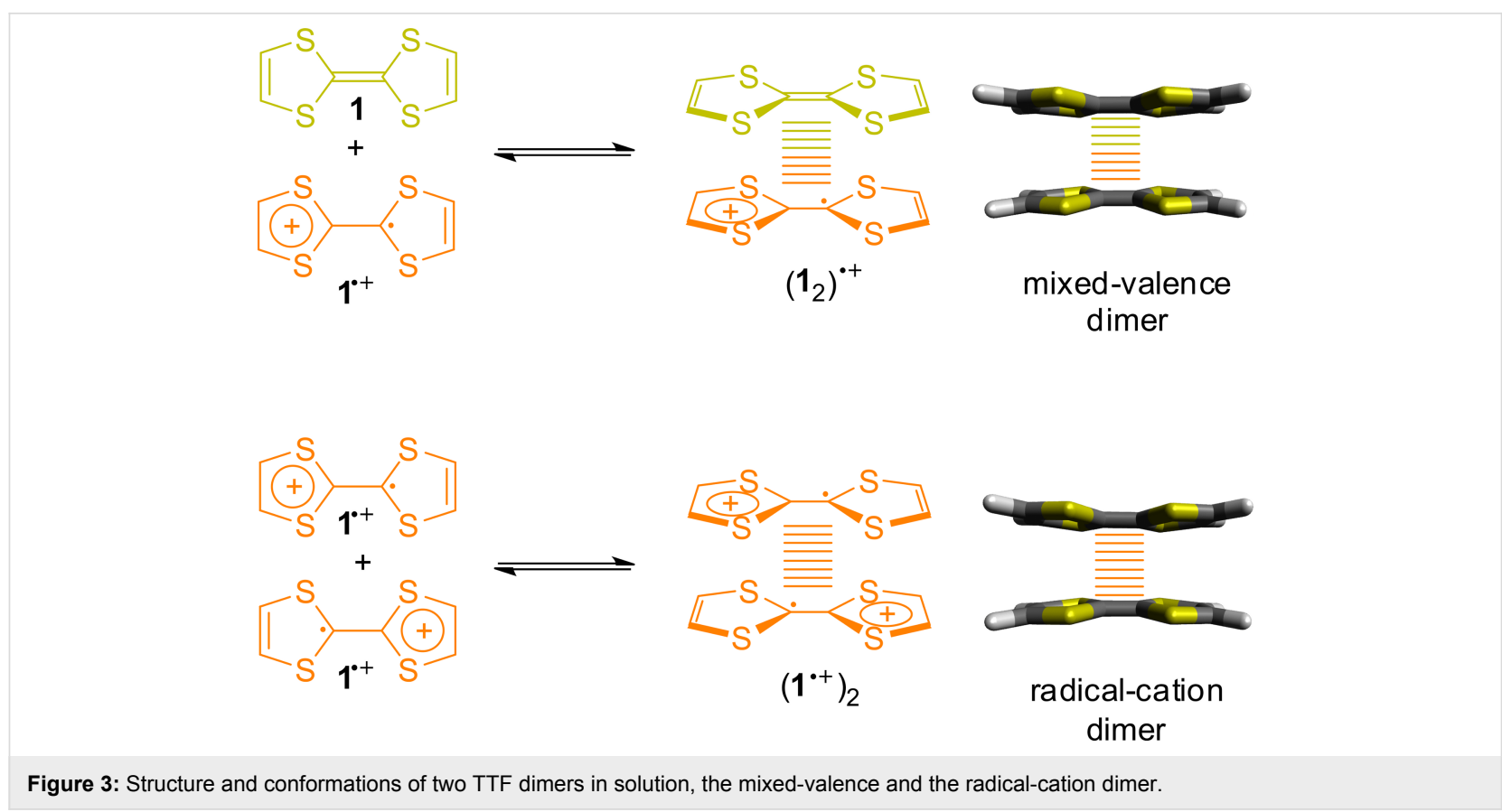

cules in the dimer is considerably large in comparison to a $\mathrm{C}-\mathrm{C}$ bond $(\approx 1.5 \AA)$, the interaction can be considered as a type of multi-centered two-electron bond with covalent character. This type of radical-cation dimer is often called a $\pi$-dimer or "pimer" and its formation "pimerization". The radical-cation dimer can be spectroscopically identified by characteristic blue shifts of $\mathrm{TTF}^{\bullet+}$ absorption bands. These "Davydov shifts" are a result of the H-aggregate-type arrangement in the dimer [34] Furthermore, the equilibrium between a paramagnetic monomer and a diamagnetic dimer makes the use of electron paramagnetic resonance (EPR) spectroscopy ideal to follow the dimerization process [36].

Mixed-valence and radical-cation interactions in the solid state are sometimes described as "conductive" and "isolating" form, respectively. However, in solution both dimers display very low stabilities with dimerization energies of only a few $\mathrm{kJ} \mathrm{mol}^{-1}$ at room temperature [36]. Therefore, these weakly associated dimers are virtually absent at ambient conditions in solution.

A strategy to stabilize the mixed-valence and radical-cation dimer even at room temperature and to overcome the entropic penalty of their formation is to facilitate a spatial proximity of two or more TTF units by a suitable covalent link $[37,38]$. This pre-organization can also be generated in supramolecular complexes with confined spaces which provide a very high local concentration and shift the equilibrium towards the dimer side. The use of TTF dimerization has been recognized lately as additional possibility to drive motion in MIMs. Recent examples will be discussed in the following section.

\section{Evolution of TTF into a key building block in switchable molecular systems}

After the first syntheses of native TTF in the early 1970s researches quickly noticed the outstanding electronic properties of this molecule $[23,39]$. One of the first observations with major impact was the unusual conducting behavior of oxidized TTF salts [40]. The discovery that TTF and the electron-deficient molecule tetracyanoquinodimethane (TCNQ) form charge-transfer salts [41] with the uncommon motif of "segregated stacks" [42] enabled numerous investigations of TTF salts regarding their application in molecular electronics [27,43], organic metals [44], or narrow-band semiconductors [45].

As often in chemical research, major synthetic or analytic breakthroughs are needed to open pathways towards new concepts and applications. Despite the intensive research on TTF during the $70 \mathrm{~s}$ and $80 \mathrm{~s}$, the incorporation of TTF into molecular systems using simple organic chemistry procedures was still challenging at that time.

One of the major synthetic breakthroughs was thus the use of cyanoethyl protective groups for TTF thiolates (Figure 4) $[46,47]$. Treatment of cyanoethyl-protected 1,3-dithiol-thiolates A with one or two equivalents of a strong base such as $\mathrm{CsOH}$ yields quantitatively the corresponding cesium thiolates $\mathbf{B}$ and D which are quite stable under standard Schlenk conditions. Addition of an alkyl halide can attach a broad range of different substituents. The cyanoethyl group allows a sequential deprotection and alkylation of 1,3-dithiole-2-thiones $\mathbf{C}$ and $\mathbf{E}$ and the corresponding TTF molecules derived from them often in very 
(a)
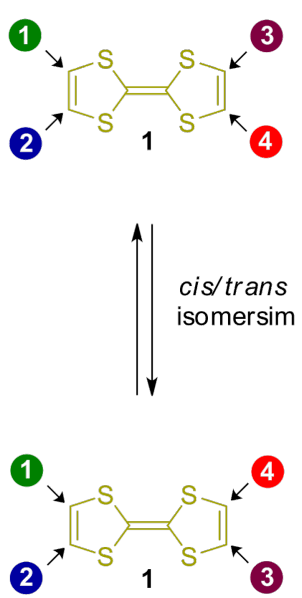

(b)

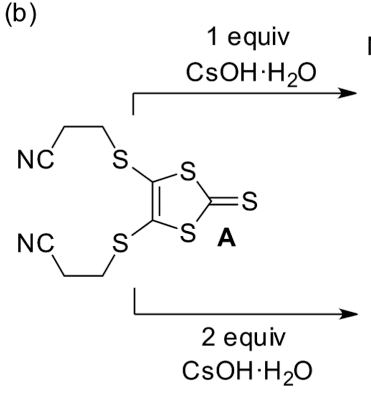<smiles>[R][X]C([Y])(Br)[I-]CCCSc1sc(=S)sc1[R5]</smiles><smiles></smiles><smiles>[R5]c1sc(=S)sc1[R5]</smiles>

(c)

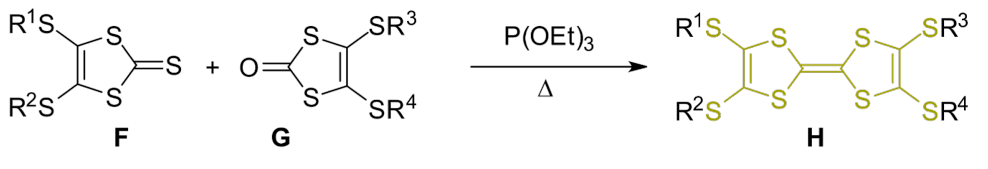

(d)<smiles>[R15]C1=C([R15])SC(=C2Sc3cn([R])cc3S2)S1</smiles><smiles>[R]n1cc2c(c1)SC(=C1Sc3cn([R])cc3S1)S2</smiles>

J

Figure 4: (a) The isomerism problem of TTF. (b)-(d) Major synthetic breakthroughs for the construction of TTF-based supramolecular architectures: (b) Stepwise deprotection/alkylation, (c) phosphite-mediated heterocoupling, and (d) pyrrolo-annulated TTF derivatives I and J.

good yields. An additional strategy to obtain non-symmetrically substituted TTF derivatives is the stepwise reaction of TTF tetrathiolate with different electrophiles [48].

Another important synthetic advance is the phosphite-mediated heterocoupling of 1,3-dithiol-2-thiones $\mathbf{F}$ and 1,3-dithiol-2-ones $\mathbf{G}$ which provides efficient access to TTFs with two differently substituted 1,3-dithiol rings in an efficient way [49]. Simple heating of both monomers (ketone and thioketone) in $\mathrm{P}(\mathrm{OMe})_{3}$ or $\mathrm{P}(\mathrm{OEt})_{3}$ yields the desired hetero dimers $\mathbf{H}$ often in good yields. In combination with transchalcogenation reactions [50], which allow the transformation of 1,3-dithiol-2-thiones into the corresponding ketones in excellent yields, various types of nonsymmetrically substituted TTF moieties can be implemented into organic systems.

However, a synthetic problem which was still intricate is caused by the four substitution sites of the TTF unit, which result in a mixture of cis and trans isomers, if two different substituents are attached to either one of the two 1,3-dithiolylidene rings. Isomerization can be promoted by trace amounts of acid [51,52] or photochemically [53]. The interconversion usually prevents a sufficient separation of the two isomers on the laboratory timescale. However, substitution of the TTF molecule by electron-withdrawing groups can stabilize the isomers [54] and a separation becomes possible. In particular when it comes to the complex intertwined structure of MIMs, an isolable pure compound is often necessary for a thorough characterization and investigation of their switching properties. One solution to the isomer problem is the introduction of mono- or bipyrrolo-annulated TTF derivatives $\mathbf{I}$ and $\mathbf{J}$ [55-57]. The incorporation of these symmetric species into MIMs often circumvents complex isomeric mixtures.

\section{Pseudorotaxanes and inclusion complexes: on the way to TTF-based MIMs}

Pseudorotaxanes have the general form of a molecular thread encircled by a macrocycle. The difference to rotaxanes is that the axle does not have bulky stopper groups that prevent the deslipping of the wheel. Thus, a pseudorotaxane forms by noncovalent interactions between host and guest without a mechanical bond. Pseudorotaxanes are important precursors of MIMs from which the construction of rotaxanes is achieved by stoppering reactions, while catenanes can be made by macrocyclization of the pseudorotaxane thread. Therefore, we discuss in the following section reports of important pseudorotaxanes and inclusion complexes that contributed to major developments of TTF-based MIMs and AMMs.

The first TTF-based pseudorotaxane was reported by Stoddart and Williams in 1991 (Figure 5) [33]. At this time, they investigated the host-guest properties of the $\pi$-electron-poor cyclo- 
(a)
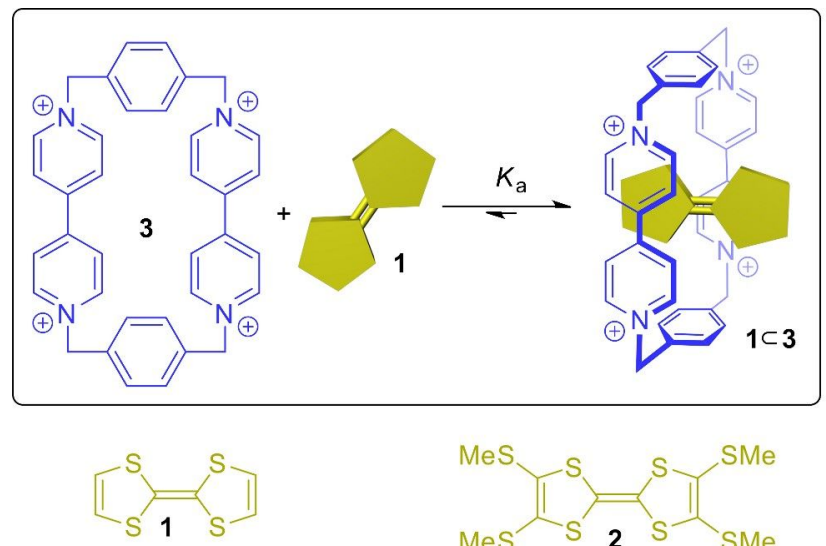

$K_{\mathrm{a}}=8,030 \mathrm{M}^{-1}$
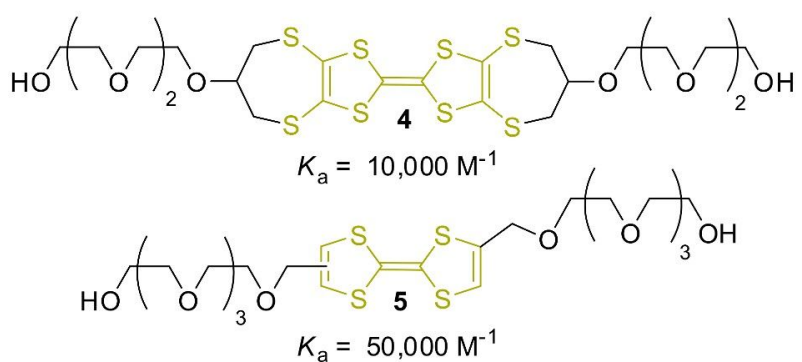

(b)
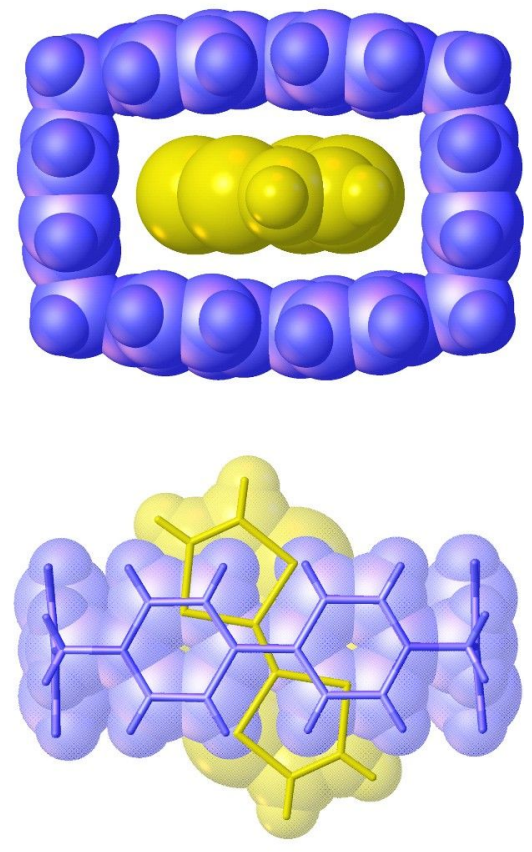

Figure 5: (a) Host-guest equilibrium between m-electron-poor cyclophane 3 and different TTFs with their corresponding association constants in $\mathrm{CH}_{3} \mathrm{CN}$. (b) Crystal structure of host-guest complex $1 \subset 3$ [33]. Solvent molecules and counterions are omitted for clarity.

phane cyclobis(paraquat-p-phenylene) (3) in form of the tetrakis(hexafluorophosphate) salt [58]. The square-shaped host complexes $\pi$-electron-rich aromatic compounds such as dihydroxynaphthalenes or dihydroxybenzenes. The $\pi$-donor TTF (1) also forms a 1:1 complex $\mathbf{1} \subset \mathbf{3}$ with this host molecule as shown in solution experiments and by crystallography. The complex formation is immediately visible by an emergent green color of these solutions due to the donor-acceptor interaction.

In later reports, differently substituted TTF derivatives as for example 2, 4, and 5 have been investigated towards their binding to host 3 [24,59-63]. $\pi$-Electron-rich TTFs form significantly stronger donor-acceptor complexes as $\pi$-electron-poor TTFs. However, also the type of substituent on the TTF moiety plays a role in terms of weak secondary binding interactions such as hydrogen bonds [63]. For example TTF 5 which is substituted by ethylene glycol chains displays a high association constant of $K_{\mathrm{a}}=50,000 \mathrm{M}^{-1}$ in acetonitrile. Additionally, extended $\pi$-surfaces [64] of TTF derivatives can have a stabilizing effect upon complexation.

TTF (1) also forms inclusion complexes with neutral host molecules such as cyclodextrins (Figure 6). This complexation is mainly driven by the hydrophobic effect. $\alpha$-Cyclodextrin (6) molecules encapsulate the hydrophobic TTF (1) in aqueous media [65]. Another water-soluble host which can complex TTFs is cucurbit[7]uril (7) [66]. However, it is not the neutral form, but the TTF radical cation $\mathbf{1}^{\bullet+}$ which is preferably bound in the cavity of this host. Even the dication $\mathbf{1}^{2+}$ can be hosted by suitable macrocycles. For example, the $\pi$-electron-rich wheel $\mathbf{8}$, consisting of two doubly-bridged 1,5-dioxynaphthalenes, is able to form a donor-acceptor complex with the $\pi$-electron-poor $\mathrm{TTF}^{2+}$ dication [26].

An astonishing discovery regarding TTF-cucurbituril complexes was made by Kim and co-workers in 2004 (Figure 7) [67]. The host molecule cucurbit[8]uril (9), which is enlarged by an additional glycoluril unit in comparison to 7 , provides sufficient space to accommodate two planar molecules with cofacial orientation [68]. When the water-soluble TTF derivative 10 gets oxidized to its radical cation $\mathbf{1 0}^{\bullet+}$, a $2: 1$ complex is formed with a radical-cation dimer $\left(\mathbf{1 0}^{\bullet+}\right)_{2}$ stabilized in the cavity of the host molecule $\mathbf{9}$. The presence of the radical-cation dimer complex $\left(\mathbf{1 0}^{\bullet+}\right)_{2} \subset \mathbf{9}$ was demonstrated by NMR, UV-vis and EPR spectroscopy. This was a novelty because stable TTF radical-cation dimers, which are usually only weakly associated species, where not characterized in aqueous medium at room temperature before. 


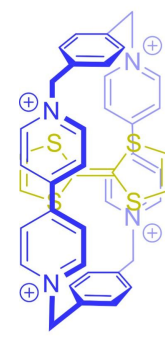

$1 \subset 3$

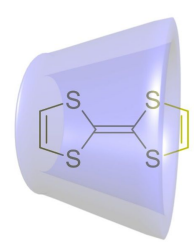

$1 \subset 6$

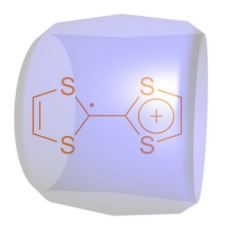

$1^{++} \subset 7$

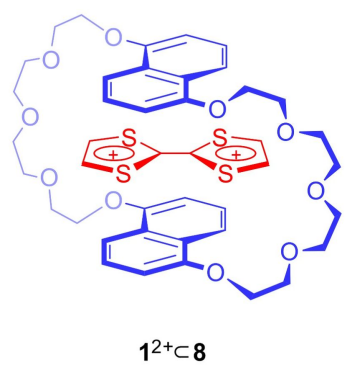

$1^{2+} \subset 8$

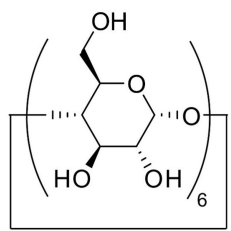

$\hat{=}$

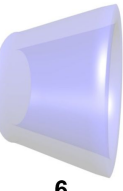

6

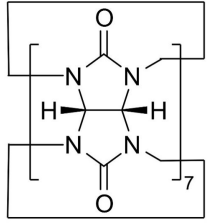

$\hat{=}$

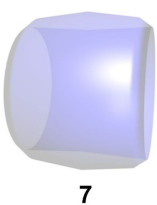

Figure 6: TTF complexes with different host molecules.

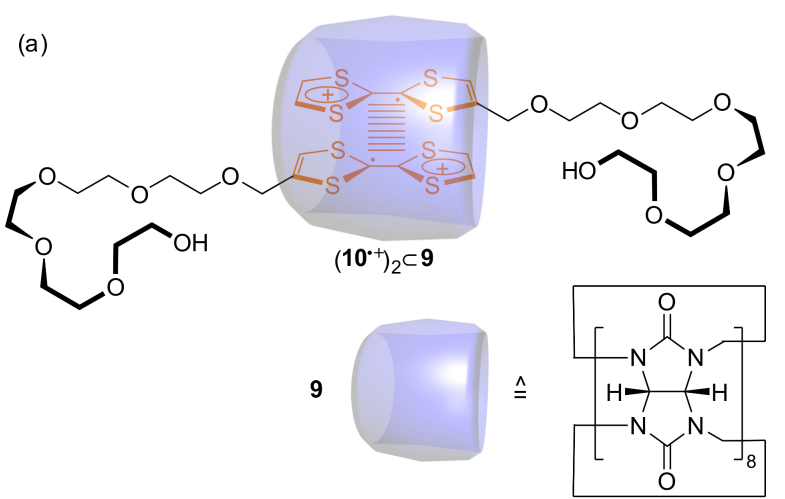

(b)

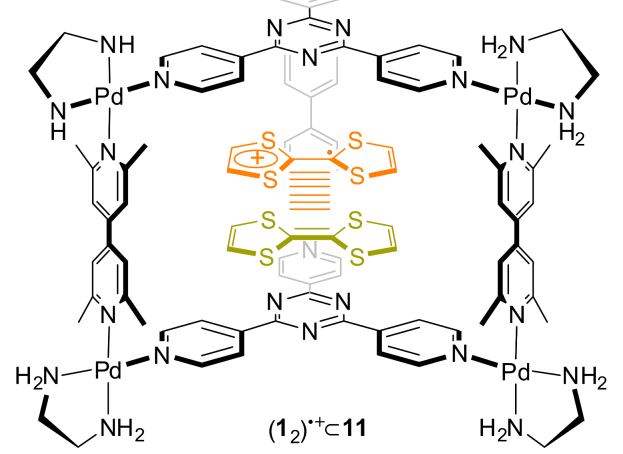

Figure 7: Stable TTF (a) radical-cation and (b) mixed-valence dimers in confined molecular spaces.

A similar observation regarding TTF dimers was made by Fujita and co-workers in 2005 [69]. They used the self-assembled Pd-cage 11 to encapsulate two neutral TTF molecules. Oxidation of the solution yields an ambient-stable TTF mixedvalence dimer $\left(\mathbf{1}_{2}\right)^{\bullet+}$ inside the cage as shown by optical and electrochemical methods.
A further step towards motion control in MIMs was made by investigating the switching of the TTF molecule when different host molecules are available in solution (Figure 8). In a so-called "three-pole supramolecular switch" consisting of a mixture of host $\mathbf{3}, \mathbf{8}$, and TTF (1), the TTF molecule can change its position like in a "pea in the shell game" [26]. In its neutral form, TTF (1) forms the donor-acceptor complex $\mathbf{1} \subset \mathbf{3}$ with host 3. Higher potentials need to be applied to oxidize TTF (1) into its radical-cationic form since the association energy of the donor-acceptor complex must be overcome. After oxidation, the radical-cation $\mathbf{1}^{\bullet+}$ is expelled from host 3 by repulsive Coulombic forces. If $\mathbf{1}^{\bullet+}$ gets further oxidized to the $\pi$-electronpoor dication $\mathbf{1}^{2+}$, the $\pi$-electron-rich macrocycle $\mathbf{8}$ can now encapsulate $\mathrm{TTF}^{2+}$. This relatively straightforward concept of electrochemically triggered complexation and expulsion of the TTF molecule from different hosts forms the fundament for motion control in a variety of different MIMs.

To illustrate how this redox-triggered complexation/decomplexation of pseudorotaxanes is transferred into a controlled molecular motion in MIMs, the TTF-based pseudo[1]rotaxane 12 recently reported by us is shown in Figure 9 [70]. In a pseudo[1]rotaxane, the axle molecule is covalently bound to the wheel component. The self-inclusion structure mimics the conformation of a molecular lasso, a structural motif which was also recently found in nature for peptides with high antibacterial efficacy [71]. In 12, the TTF molecule is not implemented in the thread but in the wheel component. In the neutral state, strong hydrogen bonding between the crown ether wheel and the dialkylammonium station forces a threaded conformation. If the TTF is oxidized, however, charge repulsion between the ammonium station and the TTF moiety weakens the binding. This ultimately leads to an expulsion of the thread from the cavity of the wheel, and thus to an opening of the lasso. This 


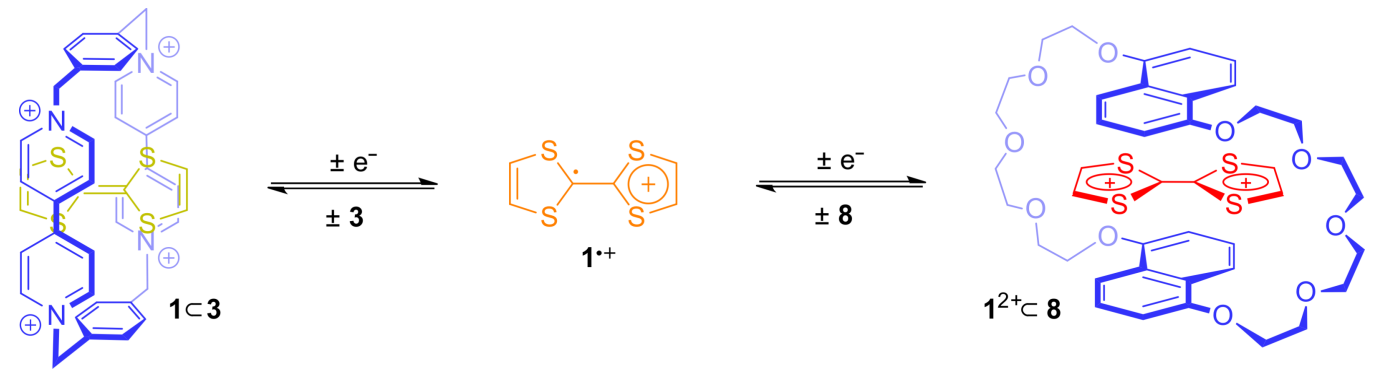

Figure 8: A "three-pole supramolecular switch": Controlled by its oxidation state, TTF (1) jumps back and forth between different host molecules.

example shows how easily a reversible molecular motion can be achieved by redox-switching of the TTF unit.

\section{Rotaxanes}

Rotaxanes consist of a dumbbell-shaped axle molecule encircled by a macrocycle. Bulky stopper groups at both ends of the axle prevent a deslipping of the wheel. With a development starting from low-yielding statistical synthesis to efficient template-controlled synthesis, rotaxanes have become the workhorse of MIMs in the last three decades. Regarding their use as molecular devices, three types of motions can be potentially controlled in rotaxanes: pirouetting of the wheel around the axle, translation of the wheel along the axle, and a rocking motion of the wheel [72]. However, most reports have focused on the stimuli-controlled translational motion. MIMs in which the wheel position on the axle is controlled by external stimuli are called "switchable molecular shuttles".

\subsection{Switchable molecular shuttles}

A schematic illustration of the working principle of non-degenerate TTF-based shuttle rotaxanes is shown in Figure 10. In the ground state co-conformation, the wheel encircles the TTF unit. Upon TTF oxidation, the attractive forces are lowered or even repulsive forces are generated between the TTF unit and

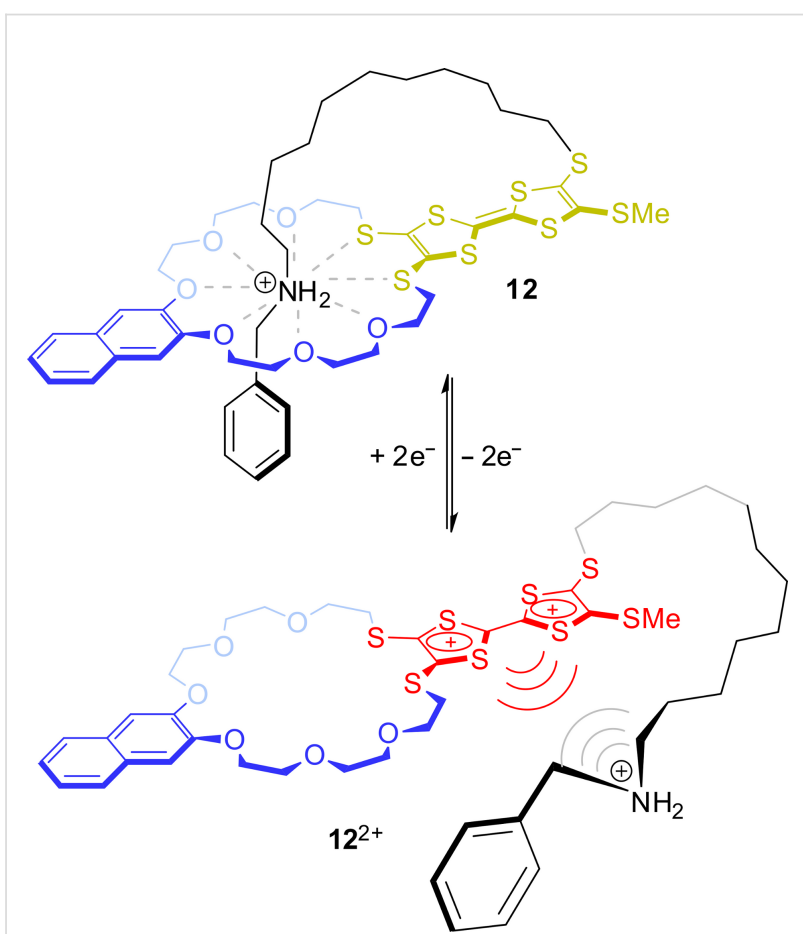

Figure 9: Redox-controlled closing and opening motion of the artificial molecular lasso 12.

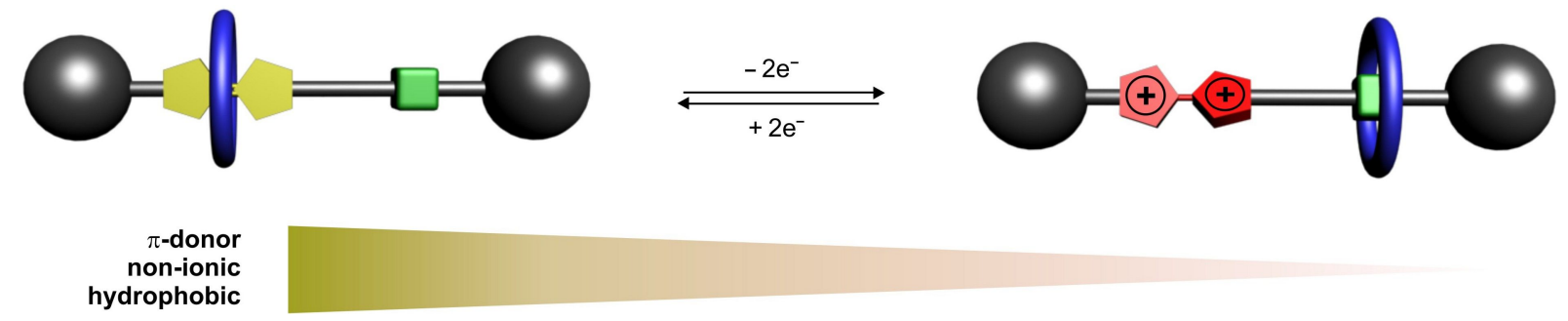

Figure 10: Graphical illustration how a non-degenerate TTF-based shuttle works under electrochemical operation. 
the wheel inducing a motion of the wheel towards the now energetically preferred green-colored binding site. Therefore, the most populated and consequently the ground-state co-conformation in the oxidized state is the wheel on the green station. Because of the reversibility of TTF redox reactions, the molecular shuttle can be reversibly switched over many cycles. The work which is generated in the operation of a molecular shuttle is reminiscent of a piston engine used for macroscopic motors. However, one should keep in mind that the transfer of the concepts of macroscopic machines to the molecular level may be limited and may even be misleading. In contrast to macroscopic piston engines, the translation of the wheel in a rotaxane occurs through Brownian motion and the switching processes cause merely a shift of the equilibrium between the two positional isomers of the rotaxane. Thus, a transfer of work on the molecular level that is created by wheel translation into a macroscopic force is quite difficult (but not impossible) to achieve.

Closely after the discovery of the donor-acceptor complex $\mathbf{1} \subset \mathbf{3}$, Stoddart and co-workers reported the synthesis of the first
TTF-based rotaxane 13 (Figure 11) [73]. The [2] rotaxane was obtained in $8 \%$ yield by a high-pressure clipping procedure in which the wheel $\mathbf{3}$ was formed around the pre-synthesized axle. In DMSO, the macrocycle is predominantly located on the central TTF moiety. However, in acetone, which has a lower polarity, the wheel moves to one of the dihydroxybenzene residues as indicated by ${ }^{1} \mathrm{H}$ NMR and UV-vis spectroscopy. Since the axle molecule is symmetric, the wheel moves back and forward between the two dihydroxybenzene stations (green) and the rotaxane can be considered as a degenerate shuttle.

Subsequently, the groups of Becher and Stoddart reported on a series of similar, but non-degenerate [2]rotaxanes [74,75]. After several structural optimizations, the bistable rotaxane $\mathbf{1 4}$ with a high switching efficiency was reported in 2003 (Figure 12) [76]. In the unswitched state, host $\mathbf{3}$ is located at the TTF binding site. Chemical oxidation to the dication $\mathrm{TTF}^{2+}$ triggers a translational motion of the wheel towards the 1,5-dihydroxynaphthalene station (green) as shown by UV-vis and 2D NMR experiments. Chemical reduction with zinc powder restored the spectroscopic properties of the starting state and back-shuttling of

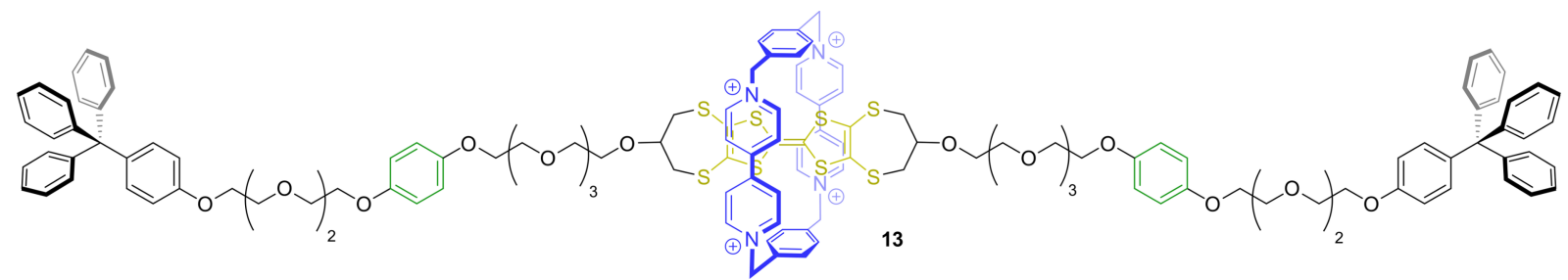

Figure 11: The first TTF-based rotaxane 13

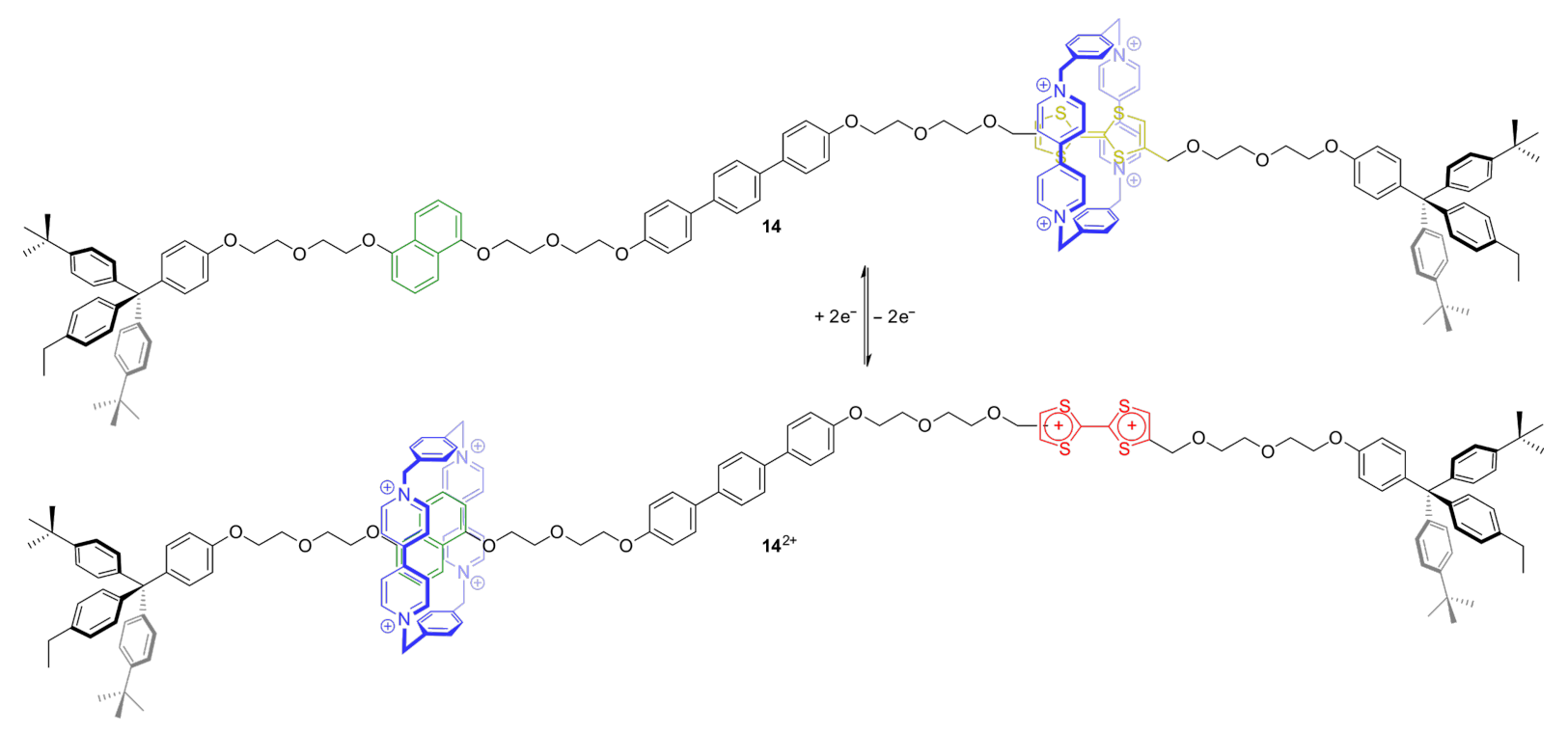

Figure 12: A redox-switchable bistable molecular shuttle 14 
the wheel to the TTF station occurs. In the $\mathrm{TTF}^{2+}$ state, no signals for a free 1,5-dihydroxynaphthalene station were observed which indicates the rotaxane to be completely switched within the detection limit of ${ }^{1} \mathrm{H}$ NMR spectroscopy. The experimental observations and the general switching mechanism of these bistable donor-acceptor rotaxanes were subsequently underpinned by several quantum mechanical studies [77-79].

The concept of TTF-based switchable rotaxanes was also extended to rotaxanes with other macrocycles. In Figure 13, the bistable [2] rotaxane $\mathbf{1 5}$ is shown with an $\alpha$-cyclodextrin (6) ring threaded onto a water-soluble axle [80]. The rotaxane was synthesized in $23 \%$ yield by a template/capping strategy where one stopper is attached using copper-catalyzed azide-alkyne click chemistry after the formation of the precursor pseudorotaxane. Due to the hydrophobic effect, the neutral TTF is preferred as a station for the wheel over the triazole unit. However, after oxidation, the more hydrophilic dication $\mathrm{TTF}^{2+}$ is less favored and the ring moves to the triazole. Both switching states were fully characterized by UV-vis, ${ }^{1} \mathrm{H},{ }^{1} \mathrm{H}-\mathrm{NOESY}$ NMR spectroscopy, and cyclic voltammetry. The latter technique revealed an increase of oxidation potential for the first one-electron oxidation, but a second oxidation potential similar to that of the free axle. This indicates that the wheel already moves away from the $\mathrm{TTF}$ station upon the first oxidation to the $\mathrm{TTF}^{\bullet+}$ radical cation.

Another example for a non-charged TTF-based rotaxane was reported in 2011 (Figure 14) [81]. Very similar to the prior bistable rotaxanes, donor-acceptor interactions dominate the relation of wheel and axle in [2]rotaxane $\mathbf{1 6}$. Here, a $\pi$-electrondeficient pyromellitic diimide macrocycle encircles a TTF station $\left(K_{\mathrm{a}}=6,300 \mathrm{M}^{-1}\right)$ which is embedded in an axle mole- cule with two azide residues. The second station, the dihydroxynaphthalene moiety (green), displays a lower association constant of $K_{\mathrm{a}}=5,800 \mathrm{M}^{-1}$. The pseudorotaxane precursor was end-capped by a double copper-catalyzed azide-alkyne click reaction in $\mathrm{CH}_{2} \mathrm{Cl}_{2}$ and the rotaxane was isolated in $34 \%$ yield. NMR spectroscopy, cyclic voltammetry, and spectroelectrochemistry showed that the wheel translates to the dihydroxynaphthalene station upon TTF oxidation.

The use of TTF in redox-switchable rotaxanes is not limited to the implementation into axle components. Very recently, our group reported on a crown/ammonium rotaxane $\mathbf{1 7}$ in which a TTF unit is implemented in the crown-ether wheel (Figure 15) [82]. The rotaxane was synthesized by a catalyst-free nitrile oxide capping strategy in $67 \%$ yield. In the neutral state, the wheel is strongly bound to the ammonium station by hydrogen bonds as shown by the high association constant of a structurally similar pseudorotaxane precursor $\left(K_{\mathrm{a}}=590,000 \mathrm{M}^{-1}\right)$. The high association constant is a result of the weakly coordinating anion (WCA) used, i.e., tetrakis(3,5-bis(trifluoromethyl)phenyl)borate. Comparison to a structurally similar rotaxane in which the ammonium station is blocked by $\mathrm{N}$-acetylation shows that the isoxazole moiety acts as a weak second binding station for the wheel. Oxidation of the TTF unit results in Coulombic repulsion between the wheel and the ammonium station which counteracts the energy of hydrogen bonding. Detailed electrochemical measurements and digital simulations revealed the ring still to be bound to the ammonium station in the $\mathrm{TTF}^{\bullet+}$ state. However, after double oxidation a wheel distribution of $1: 1$ between the ammonium and the isoxazole station was found indicating a dynamic motion between both stations.<smiles></smiles><smiles></smiles>

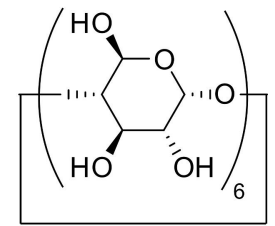

$\hat{=}$

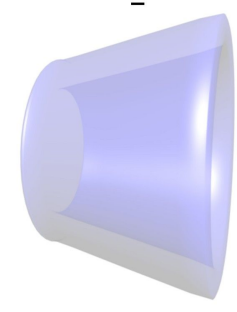

Figure 13: The redox-switchable cyclodextrin-based rotaxane 15. 


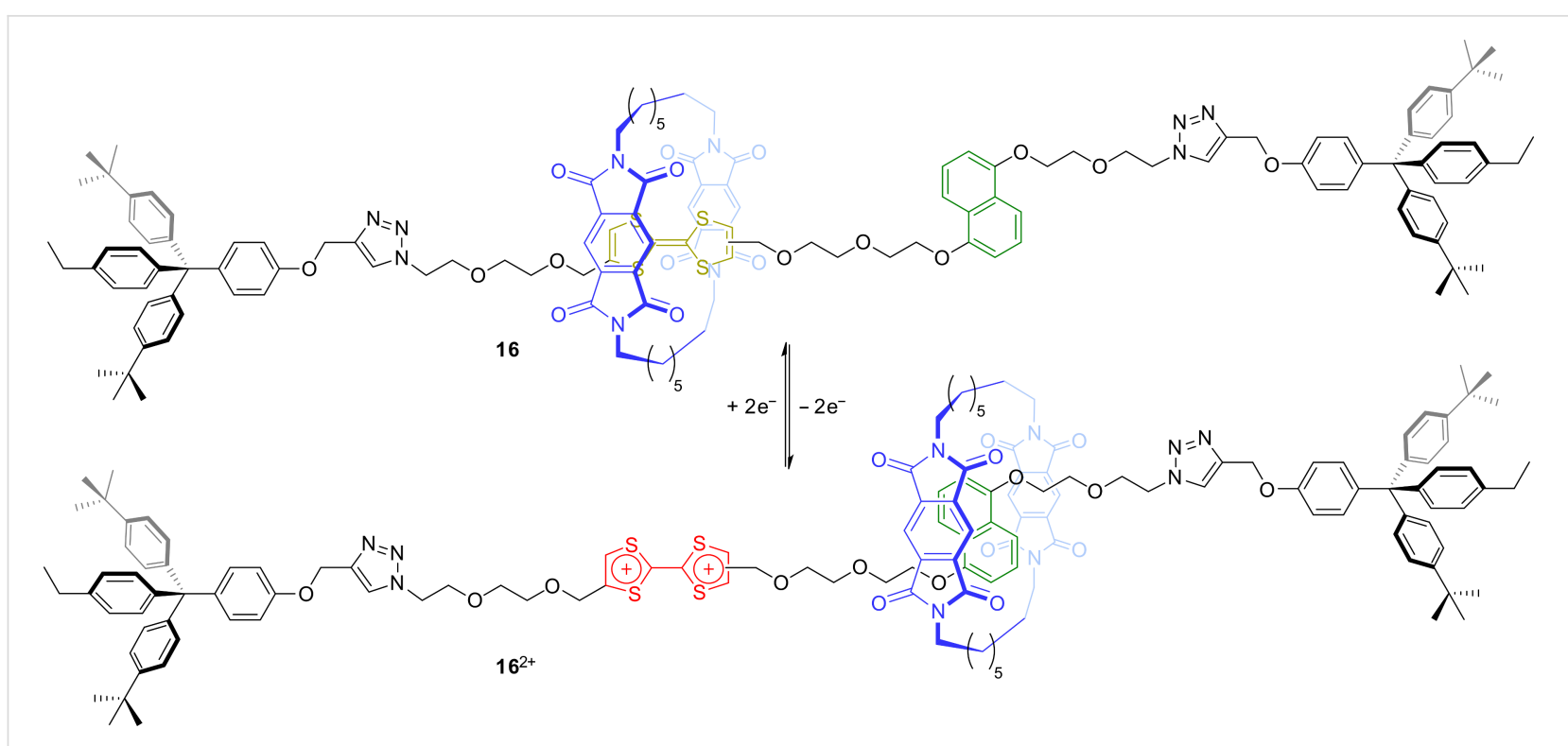

Figure 14: The redox-switchable non-ionic rotaxane 16 with a pyromellitic diimide macrocycle.

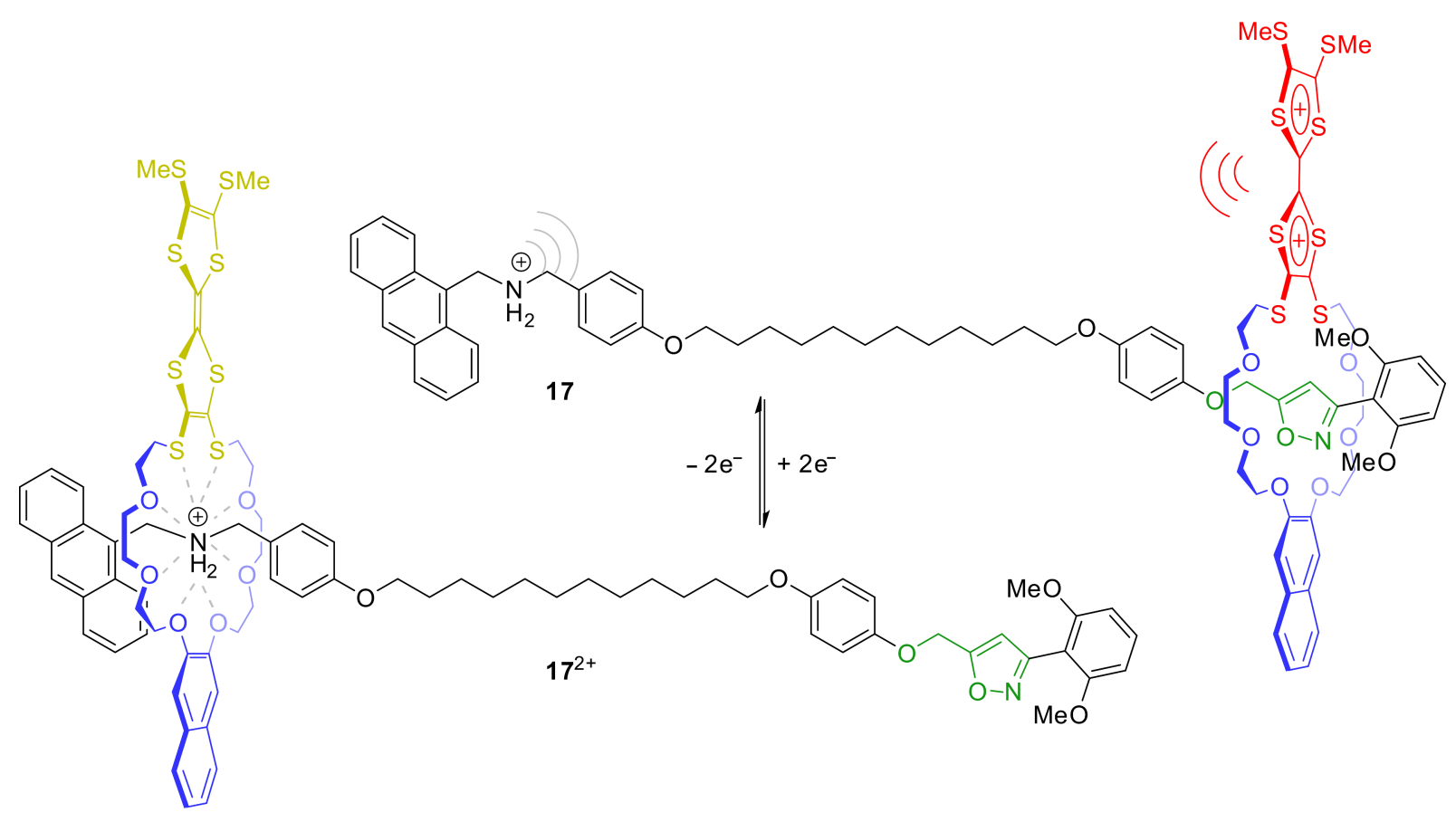

Figure 15: The redox-switchable TTF rotaxane 17 based on a crown/ammonium binding motif.

\subsection{Optical devices}

The rapid development of redox-switchable MIMs led to considerations to use the unique properties of these molecules for different optoelectronic devices. TTF-based MIMs often display very long-living and stable switching states which are particularly appealing for applications as data storage devices [83] or molecular logic gates [84]. Besides simple molecular electrochromic switches, complex TTF-based MIMs with unique optical properties have been constructed.

In 2012, rotaxane $\mathbf{1 8}$ with a structure similar to previously reported donor-acceptor rotaxanes was reported (Figure 16) [85]. However, the axle bears a central azobenzene photoswitch, who's E/Z-transitions can be controlled by light. The redox- 


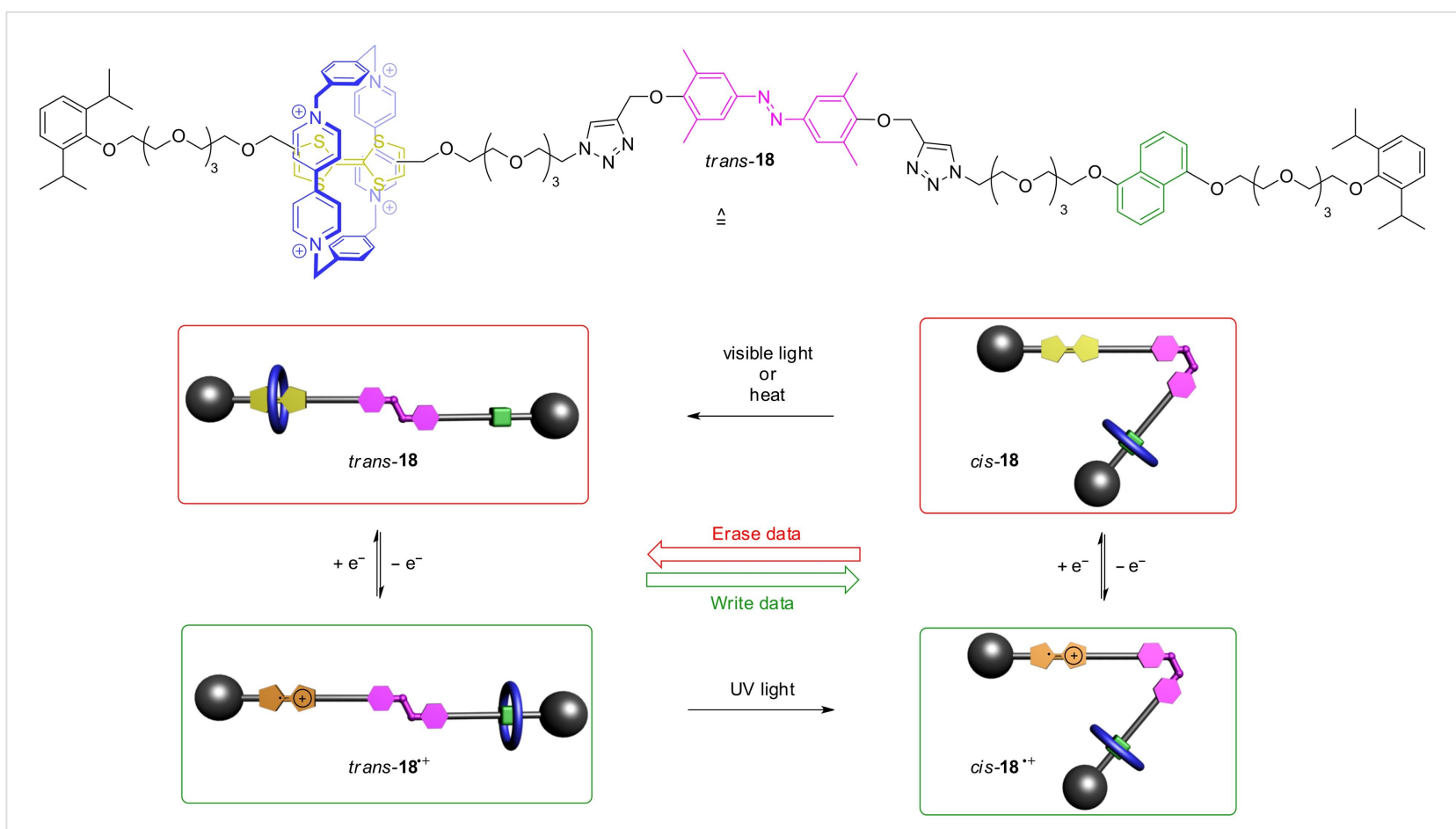

Figure 16: Structure and operation of the electro- and photochemically switchable rotaxane 18 which acts as potential memory device.

switchable shuttle works as previously described and the position of the wheel can be controlled by oxidation or reduction. However, the configuration of the azobenzene strongly influences the life time of each redox-switching state. In the $(E)$ form, the wheel can easily move between the TTF and dihydroxynaphthalene station. In the $Z$-form, this movement is sterically hindered and slowed down. The wheel cannot shuttle to its energetically preferred station. This possibility of orthogonal switching (redox and light) enables an electrochemical "writing" of data which can be subsequently locked by a light stimulus.

The TTF-based doubly interlocked crown/ammonium rotaxane 19 recently reported by us consists of a divalent axle with a $\pi$-electron-poor central naphthalene diimide (NDI) unit and a divalent crown-ether wheel with a central TTF unit (Figure 17) [86]. The cofacial donor-acceptor complex whose formation is indicated by a deep green color is forced to stay in a cofacial orientation by mechanical bonding, even when the complex is redox-switched. UV-vis spectroscopy showed the emergent charge-transfer absorption band to display a negative solvochromic effect. Similar to TTF, the NDI unit has three stable oxidation states. However, these are neutral or anionic states and successive reduction of NDI leads to the radical anion and the dianion. Cyclic voltammetry, DFT calculations, and UV-vis spectroscopy confirmed five different redox states
$\left(\mathrm{TTF} / \mathrm{NDI}, \mathrm{TTF}^{\bullet+} / \mathrm{NDI}, \mathrm{TTF}^{2+} / \mathrm{NDI}, \mathrm{TTF} / \mathrm{NDI}^{\bullet-}, \mathrm{TTF} / \mathrm{NDI}^{2-}\right.$ ) and shows interesting optical properties in each of these redox states making this type of mechanically constrained donor-acceptor complex very interesting for molecular electronic materials and optoelectronic devices.

\subsection{TTF-Based rotaxanes on solid support}

If one aims at creating macroscopic effects, the concerted action of many molecular machines is needed. It is then useful to deposit switchable AMMs on interfaces such as a surface of a solid support [87-89]. An ordered array of molecules enables the possibility of concerted switching. The fixed orientation on a surface allows studying molecules with sophisticated techniques such as scanning tunneling microscopy. Furthermore, redox-switchable AMMs, containing for example TTF moieties, can be electrically operated without the need of chemical additives, if conducting solid supports are used. This also opens pathways towards the integration of switchable AMMs into the world of silicon-based chips and electronic circuits.

A landmark in the field of molecular-scale electronic devices is the rotaxane-based 160-kilobit memory which was reported by the groups of Stoddart and Heath in 2007 (Figure 18) [90]. The key idea of this memory is that the switching modes in a bistable rotaxane $\mathbf{2 0}$ can be considered as the " 1 " and " 0 " states of a binary digit. If the rotaxane shows a hysteretic cur- 


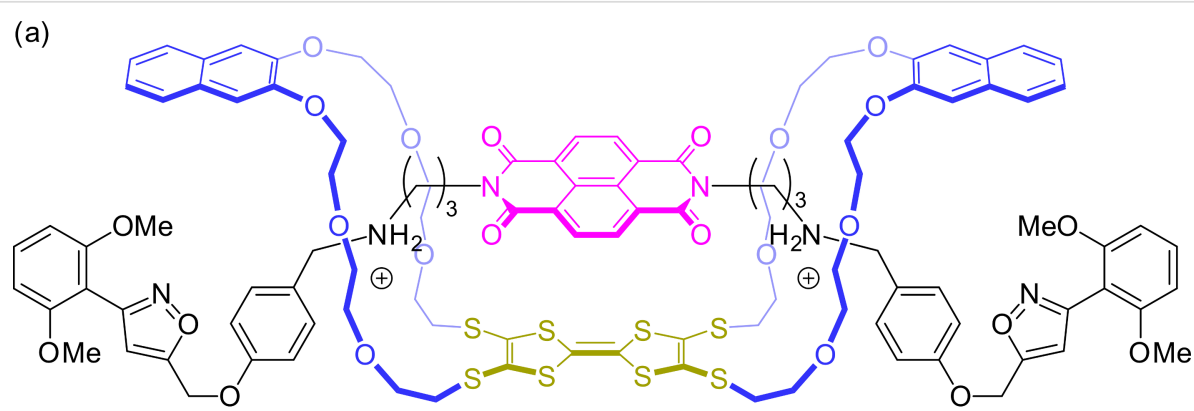

19

(b)

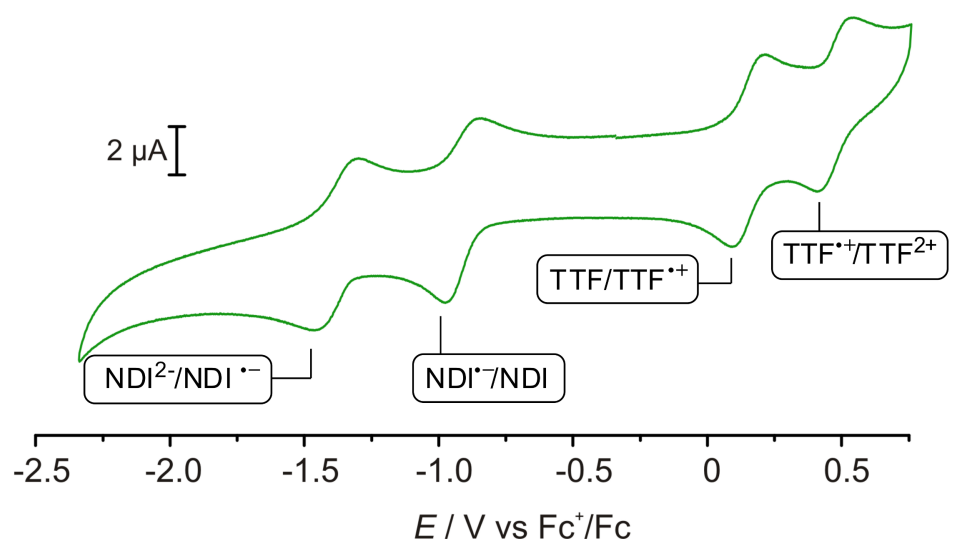

Figure 17: (a) The redox-switchable rotaxane 19 with a donor-acceptor pair which is stable in five different switching states. (b) Cyclic voltammogram showing the transitions between the five oxidation states of 19.

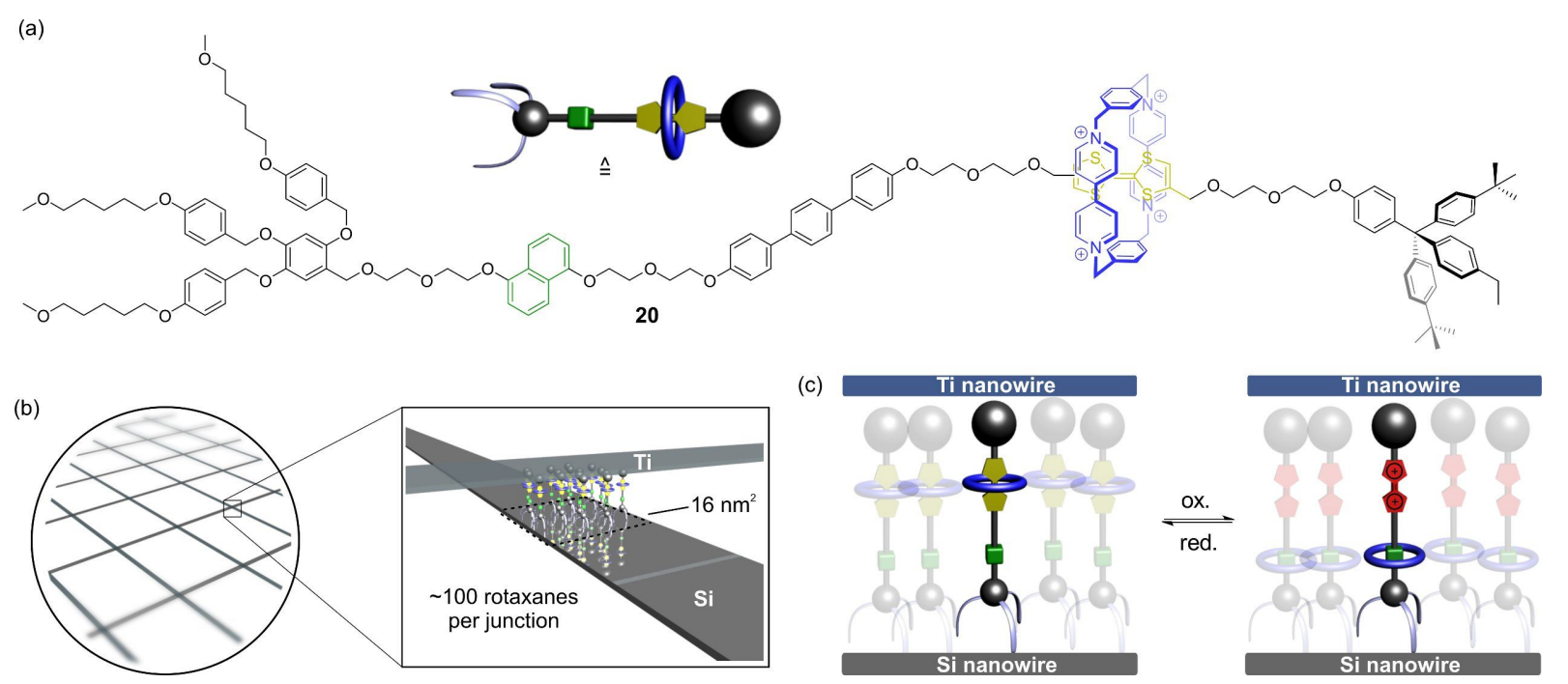

Figure 18: Schematic representation of a molecular electronic memory based on a bistable TTF-based rotaxane. (a) Molecular structure of the amphiphilic [2]rotaxane 20. (b) Structure of the crossbar device. (c) Switching mechanism of rotaxane 20 in a junction.

rent-voltage curve, a voltage-induced reading and writing of information becomes possible. Although the initial concept of this type of device was developed a few years earlier [91], the optimization of its structure and fabrication was necessary to reach high-level performance [92-94].
The device is based on a crossbar architecture in which a monolayer of amphiphilic rotaxanes is sandwiched by a bottom $\mathrm{Si}$ nanowire electrode and a top Ti nanowire electrode. Both layers of nanowires are orthogonal to each other. This produces several crossing points or "junctions" whose areas are defined 
by the diameter of the nanowires. In the present example, a very small diameter gives a junction area of only $16 \mathrm{~nm}^{2}$ which corresponds to approximately 100 rotaxanes per junction. When a high pulse voltage is applied $( \pm 1.5 \mathrm{~V})$, the junctions can be switched back and forward between the two switching states of the rotaxane. The written information is then read out by a nonperturbing lower voltage. It turned out that the terphenyl spacer which is implemented into the rotaxane axle is crucial to increase the half-life of the metastable switching state. However, a disadvantage of this particular device was a high fraction of "defect" junctions. Only $\approx 25 \%$ showed a sufficient on/off ratio for a memory device. Furthermore, only a limited number of switching cycles was possible before the junctions were damaged. However, a remarkably high storage density of $10^{11}$ bits $\mathrm{cm}^{-1}$ was reached.

Writing of data with the aid of dendrimer-decorated TTF-rotaxanes was achieved by Gao and co-workers [95]. They deposited a thin-film of bistable donor-acceptor rotaxanes on an indium tin oxide (ITO)-coated substrate. A clean electrochemical switching on the substrate was observed with current-voltage curves showing a clear memory effect. The written data could be read out even after waiting for $12 \mathrm{~h}$.

Besides data storage, a substantial challenge of AMMs is the transfer of molecular motion into a useful macroscopic output. An example of rotaxanes on a solid support which could achieve this is shown in Figure 19 [96]. The [3] rotaxane 21 consists of a symmetric axle molecule in which both axle halves bear a TTF and a hydroxynaphthalene station. In the unswitched state, each TTF station is encircled by a wheel. Oxidation of the TTF units then induces shuttling motions towards the inner hydroxynaphthalene stations, which significantly reduces the wheel-wheel distance. If both wheels are attached to a surface with a suitable anchor, the shuttle motion can be seen as a type of muscle-like contraction generating tensile stress on the sur-

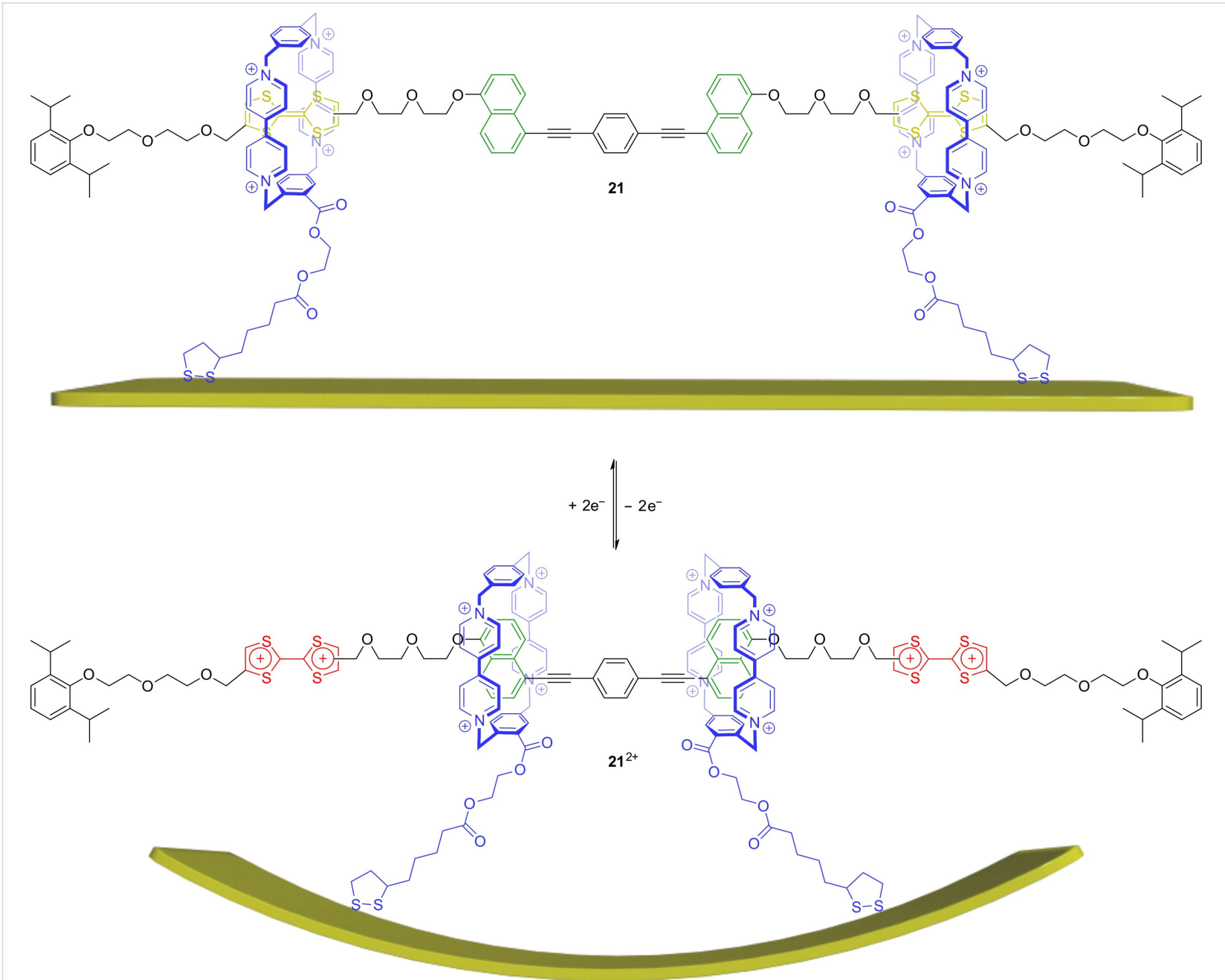

Figure 19: Schematic representation of bending motion of a microcantilever beam with gold surface induced by operation of the redox-switchable [3]rotaxane 21 attached to its surface. 
face. Although the force of one contracting rotaxane is quite small, a sufficient number of these "molecular muscles" can accumulate their force and consequently deform a material by concerted switching.

In rotaxane 21, the two macrocycles are attached by disulfide anchors to the gold surface of microcantilever beams $(500 \times 100 \times 1 \mu \mathrm{m})$ and form a self-assembled monolayer. Chemical oxidation leads to a bending and to an upward motion of the beams by $\approx 35 \mathrm{~nm}$. The addition of ascorbic acid as reductant restores the initial position and the switching cycle can be repeated. To exclude other triggers than the rotaxane contraction, several control experiments were performed. Furthermore, a structurally similar but mechanically inert control compound was synthesized which cannot induce the bending effect.

\subsection{TTF Pairing interactions in rotaxanes}

Although TTF is widely used in switchable molecular shuttles, rotaxanes with TTF-dimer interactions are rare. One example was published by Stoddart and co-workers in 2008 (Figure 20) [97]. The tripodal [4]rotaxane 22, consisting of a trivalent axle, in which each arm is encircled by a host molecule 3 , was synthesized by a copper-catalyzed click protocol in $40 \%$ yield. A combination of electrochemical and spectroscopic methods was used to investigate a potential TTF-dimer formation. As comparison, they characterized also the trivalent dumbbell precur-

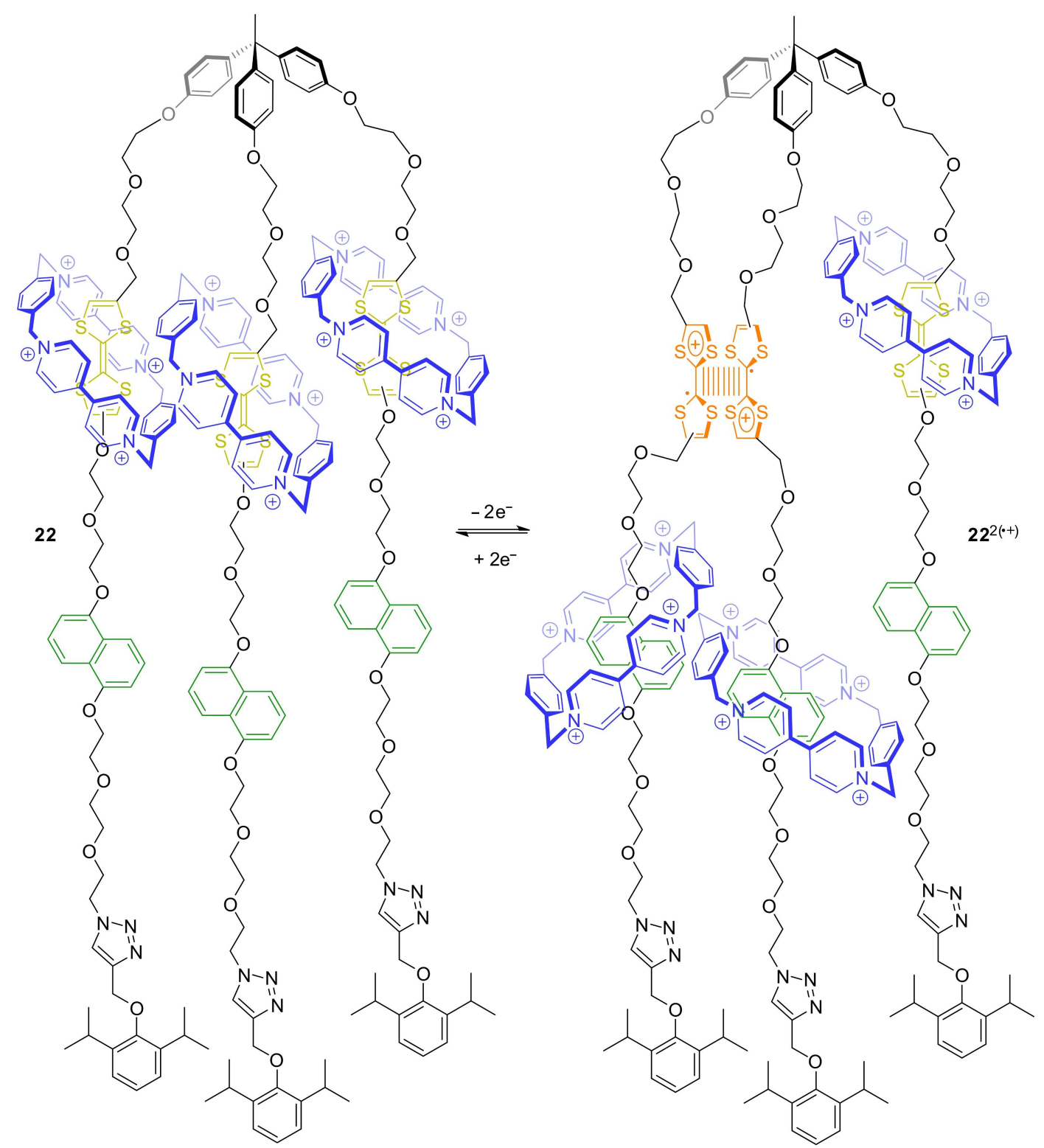

Figure 20: TTF-dimer interactions in a redox-switchable tripodal [4]rotaxane 22. 
sor without wheels. It was shown that mixed-valence interactions $\left(\mathrm{TTF}_{2}\right)^{\bullet+}$ and radical-cation interactions $\left(\mathrm{TTF}^{\bullet+}\right)_{2}$ are present during the successive oxidation of the free axle. However, only the radical-cation dimer interaction was observed in the case of [4]rotaxane 22. This discrepancy can be explained by a simple energy balance. For a mixed-valence interaction, at least two TTF/TTF ${ }^{\bullet+}$ units need to be free. Thus, after one-electron oxidation which liberates one $\mathrm{TTF}^{\bullet+}$ from the cavity of $\mathbf{3}$, still the energy of one donor-acceptor complex has to be overcome to enable a mixed-valence interaction. This is not the case for the free trivalent axle. After double oxidation, two $\mathrm{TTF}^{\bullet+}$ stations are free and a radical-cation interaction is favored. This example nicely shows that all energy contributions in each switching state of a system as a whole need to be considered for the design and operation of an AMM.

In addition to the variety of TTF-based rotaxane shuttles, we recently reported a [3]rotaxane in which the pirouetting motion of wheels can be controlled by electrochemical switching [98]. Figure 21 shows the [3] rotaxane $\mathbf{2 3}$ which bears two cofacially oriented TTF crown ethers on a divalent ammonium axle. The distance between the wheels is convenient for TTF-dimer interactions. In the non-switched neutral state of both TTFs, the wheels adopt a syn co-conformation caused by weak non-covalent interactions between the wheels. One-electron oxidation yielding $\mathbf{2 3}^{\bullet+}$ enables mixed-valence interactions $\left(\mathrm{TTF}_{2}\right)^{\bullet+}$ between the cofacial TTF units. This TTF-dimer interaction "clutches" the two wheels and synchronizes their pirouetting motions around the axle. Also the next stable oxidation state $\left(\mathbf{2 3}^{2(\bullet+)}\right)$ shows attractive wheel-wheel interactions in form of a TTF radical-cation dimerization $\left(\mathrm{TTF}^{\bullet+}\right)_{2}$. However, further oxidation leads to the fully oxidized $\mathbf{2 3}^{4+}$ in which both $\mathrm{TTF}^{2+}$ units repeal each other. The Coulombic repulsion "declutches" the two wheels and they adopt an anti co-conformation. As shown by experiments and quantum chemical calculations, the wheels cannot be fully disengaged; however, the wheel-wheel interactions strongly differ for the different oxidation states. The controlled clutching and declutching of $\mathbf{2 3}$ by electrochemical stimuli is reminiscent of the operation of a macroscopic friction clutch, a common technical device used in motor vehicles. Furthermore, rotaxane $\mathbf{2 3}$ can be used as novel supramolecular gearing system for the transmission of rotational motion at the molecular level.

\section{Rotacatenanes}

In 2011, the group of Stoddart described the fusion of a rotaxane and a catenane, a so-called "rotacatenane" (Figure 22) [99]. The rotacatenane $\mathbf{2 4}$ consists of their previously used rotaxane framework except that the enlarged cyclophane cyclobis(paraquat-4,4'-biphenylene) is used as wheel component. The cavity of this macrocycle is large enough to host two planar molecules in a cofacial arrangement. Starting from the pre-assembled catenane, the axle molecule is threaded through the wheel and end-capped by a copper-catalyzed click reaction.

A variety of different spectroscopic and electrochemical methods was applied to reveal the switching behavior of $\mathbf{2 4}$ and its stable co-conformations in each switching state. In the (a)

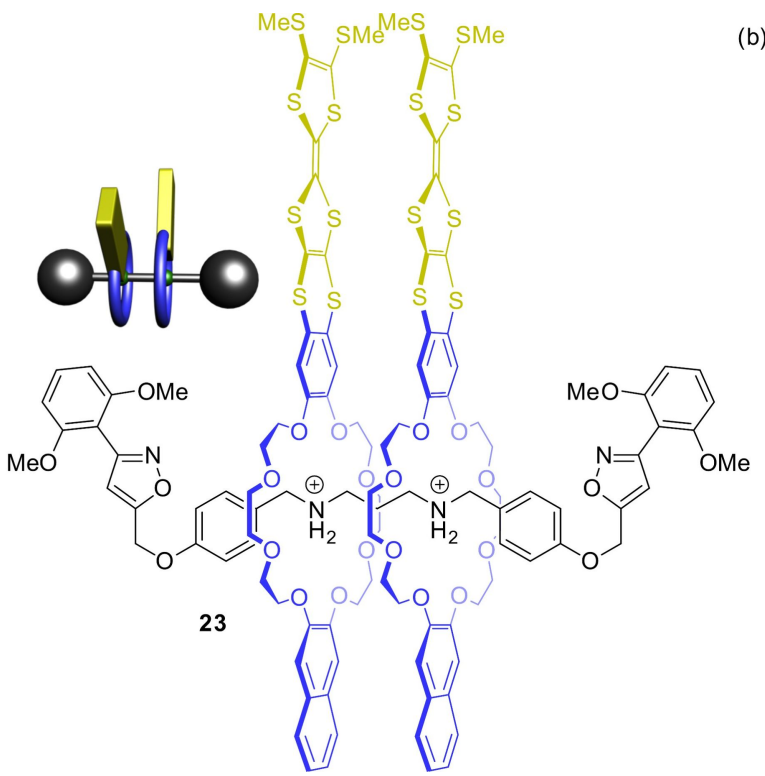

(b)
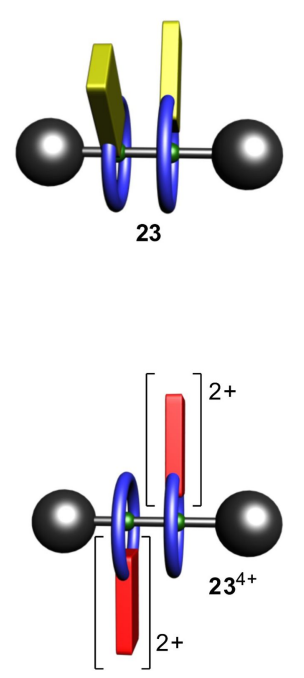

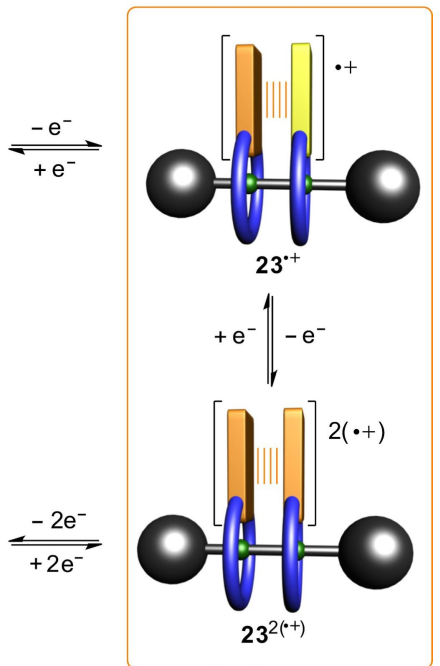

Figure 21: (a) A molecular friction clutch $\mathbf{2 3}$ which can be operated by electrochemical stimuli. (b) Schematic representation of $\mathbf{2 3}$ in its four stable oxidation states with corresponding wheel co-conformations. 


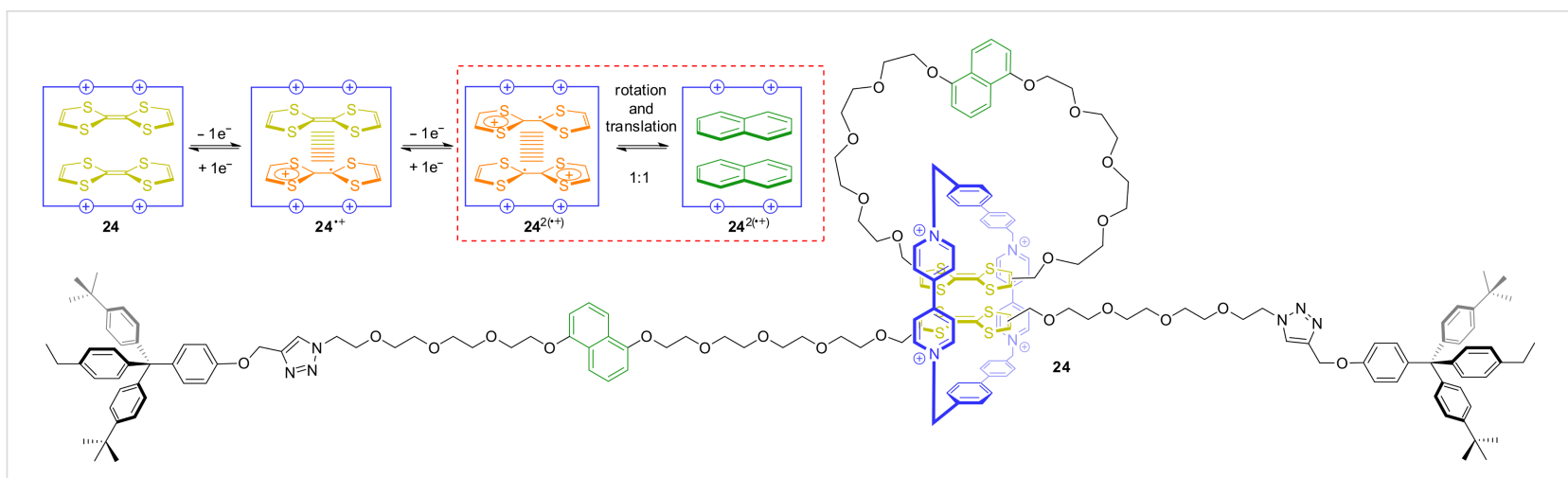

Figure 22: Fusion between rotaxane and catenane: a [3]rotacatenane $\mathbf{2 4}$ which can stabilize TTF dimers.

unswitched state, both TTF units are stacked in the cavity of the wheel. One-electron oxidation to $\mathbf{2 4}^{\bullet+}$ creates a stabilized mixed-valence interaction between these units as evidenced by an emergent NIR band. Further oxidation, converts the two TTF units into a radical-cation dimer $\left(\mathrm{TTF}^{\bullet+}\right)_{2}$. However, the Coulombic repulsion in this six-fold charged complex destabilizes the radical-cation dimer and the system converts into a second stable co-conformation in which both dihydroxynaphthalene units are inside the cavity of the wheel. To achieve this conformer, two types of motion, a circumrotation and a translational motion, must occur. The equilibrium between these two co-conformations of $24^{2(\bullet+)}$ was determined to be approximately $1: 1$. Further oxidation drives the equilibrium completely to the side of the co-conformation in which both dihydroxynaphthalene units are encircled. This TTF-based system is an intriguing example of synergetic molecular motions triggered by redox stimuli.

\section{Catenanes}

Catenanes consist of at least two intertwined macrocycles which are mechanically interlocked. The structure cannot be opened without breaking a covalent bond. In contrast to rotaxanes in which the wheel is only held on the axle component by steric hindrance of stopper groups, a catenane is a truly topologically interlocked species bearing a mechanical bond. However, the construction, chemical behavior, and operation of structurally related rotaxanes and catenanes are often very similar. The motion which can be controlled by external stimuli is the rotation (or circumrotation) of the wheels relative to each other.

The first TTF-based catenane $\mathbf{2 5}$ was described by the groups of Becher and Sauvage in 1994 (Figure 23) [100]. Starting from a phenanthroline macrocycle bearing a TTF unit, a copper(I)-template was used to obtain the TTF-based catenane 25 in $14 \%$ yield, which was previously developed by Sauvage [101] The authors aimed for a further development of this construction motif towards donor-acceptor rotaxanes with efficient charge separation leading to a broad variety of topologically complex TTF catenanes and cage compounds [52,74,102-104].

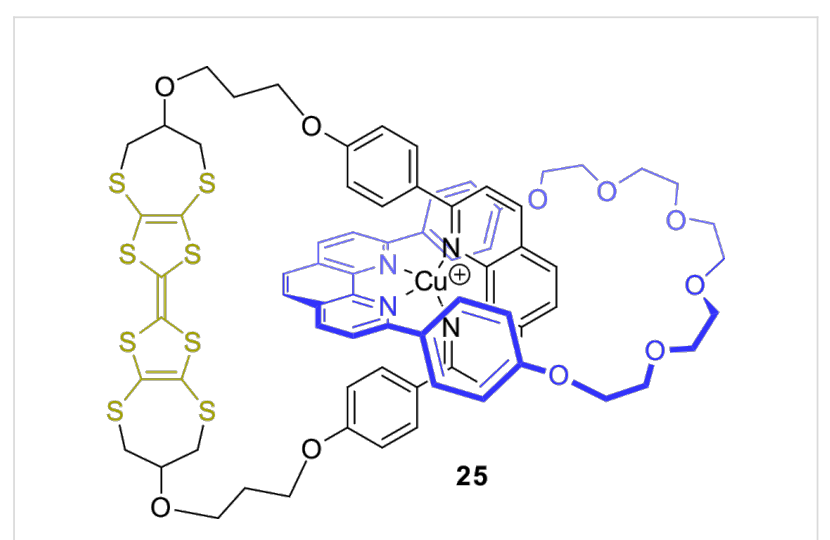

Figure 23: The first TTF-based catenane 25

\subsection{Stimuli-responsive circumrotation}

The TTF-based catenane $\mathbf{2 6}$ allows implementing a stimuliresponsive circumrotation motion (Figure 24) [105]. Similar to the corresponding donor-acceptor rotaxanes, the macrocycle preferentially encircles the TTF unit instead of the dihydroxynaphthalene station in the unswitched state. As shown by ${ }^{1} \mathrm{H}$ NMR and UV-vis spectroscopy as well as cyclic voltammetry, chemical oxidation to the $\mathrm{TTF}^{2+}$ dication triggers an expulsion of the former station and the wheel moves to the alternative dihydroxynaphthalene station. Chemical reduction with ascorbic acid or $\mathrm{Na}_{2} \mathrm{~S}_{2} \mathrm{O}_{5}$ restores the initial spectroscopic properties and the initial co-conformation of the catenane.

A tristable molecular switch based on a [2]catenane with three different stations was created by Wasielewski, Stoddart, and co-workers in 2015 (Figure 25) [106]. The catenane 27 is made of a macrocycle with a TTF, a 4,4'-bipyridinium and a dihydroxynaphthalene recognition site which is encircled by a cyclobis(paraquat- $p$-phenylene) wheel. In the resting state, the 


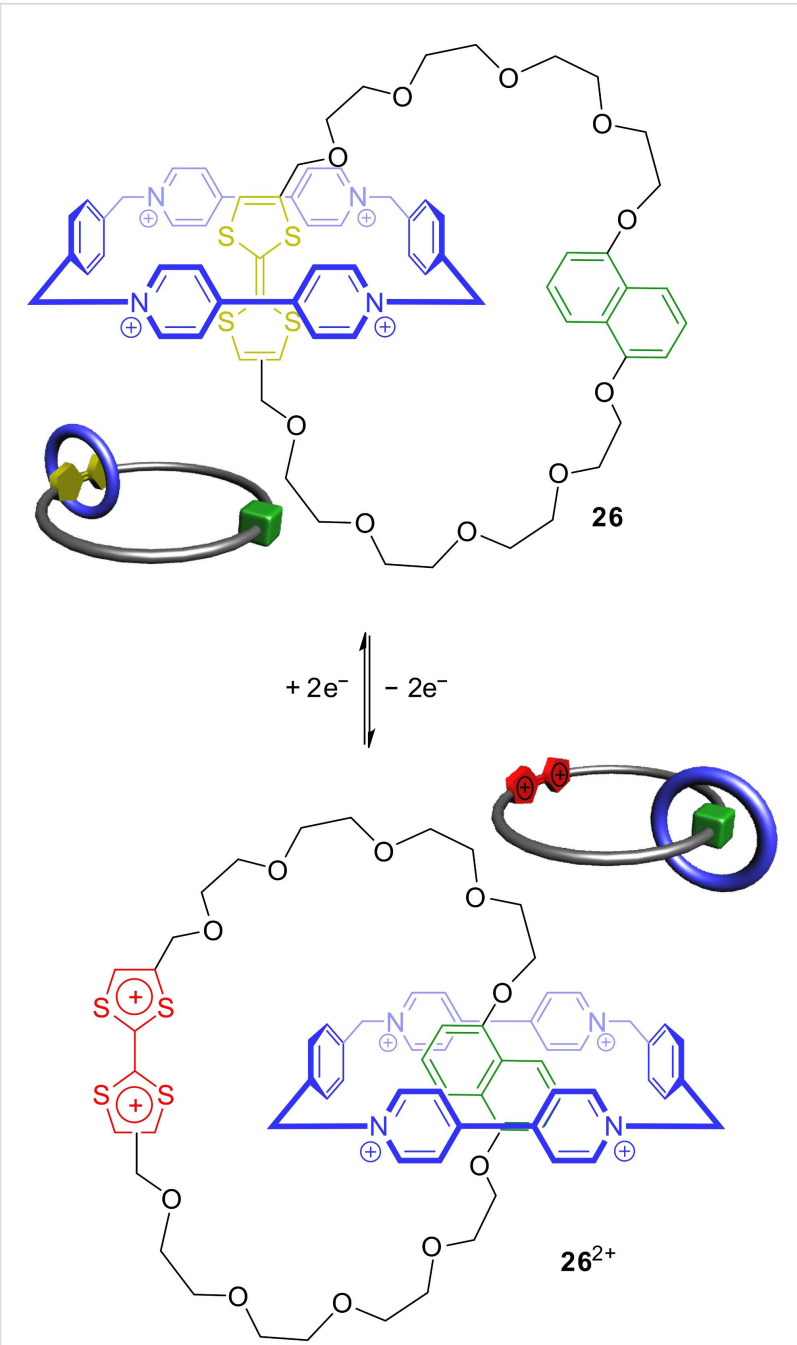

Figure 24: Electrochemically controlled circumrotation of the bistable catenane 26 . wheel is located at the TTF unit forming a donor-acceptor complex with a green color. Oxidation moves the ring to the second $\pi$-electron-rich station, the dihydroxynaphtalene. This donor-acceptor complex has a reddish color. However, in contrast to other bistable catenanes, the third 4,4'-bipyridinium station is also redox-active. Reduction of the system leads to a 4,4'-bipyridinium radical cation which forms a purple trisradical complex with the doubly reduced cyclobis(paraquat- $p$ phenylene). Electrochemical and several spectroscopic techniques showed that, overall, six stable oxidation states - each of them with a unique color - and three co-conformations are accessible in this single compound.

\subsection{Switchable catenanes in ordered arrays}

Besides ordered arrays on surfaces, on nanoparticles or in Langmuir-Blodgett films, a possibility to arrange bistable catenanes in an ordered fashion is to incorporate them into the rigid scaffold of a metal-organic framework (MOF) [107]. An advantage of this strategy is that the relatively labile organic switches are protected from degradation in this solid material. In 2016, the groups of Hupp, Farha, and Stoddart reported on a bistable donor-acceptor catenane $\mathbf{2 8}$ which is inserted in the $\mathrm{Zr}$-based MOF NU-1000 (Figure 26) [108]. The MOF NU-1000 consists of $\mathrm{Zr}_{6}$ nodes which are bridged by 1,3,6,8-tetrakis( $p$ carboxyphenyl)pyrene ligands [109]. Four hydroxy groups of each metal cluster are pointing into the mesoporous channels of the MOF and can be post-functionalized. Similar to a previous report about rotaxanes implemented into a MOF [110], the catenane was attached to the MOF framework by a so-called solvent-assisted ligand incorporation protocol. A degree of incorporation of $\approx 0.65$ catenanes per $\mathrm{Zr}_{6}$ node could be achieved as shown by ${ }^{1} \mathrm{H}$ NMR and coupled plasma atomic emission spectroscopy. This degree of functionalization results in a density of

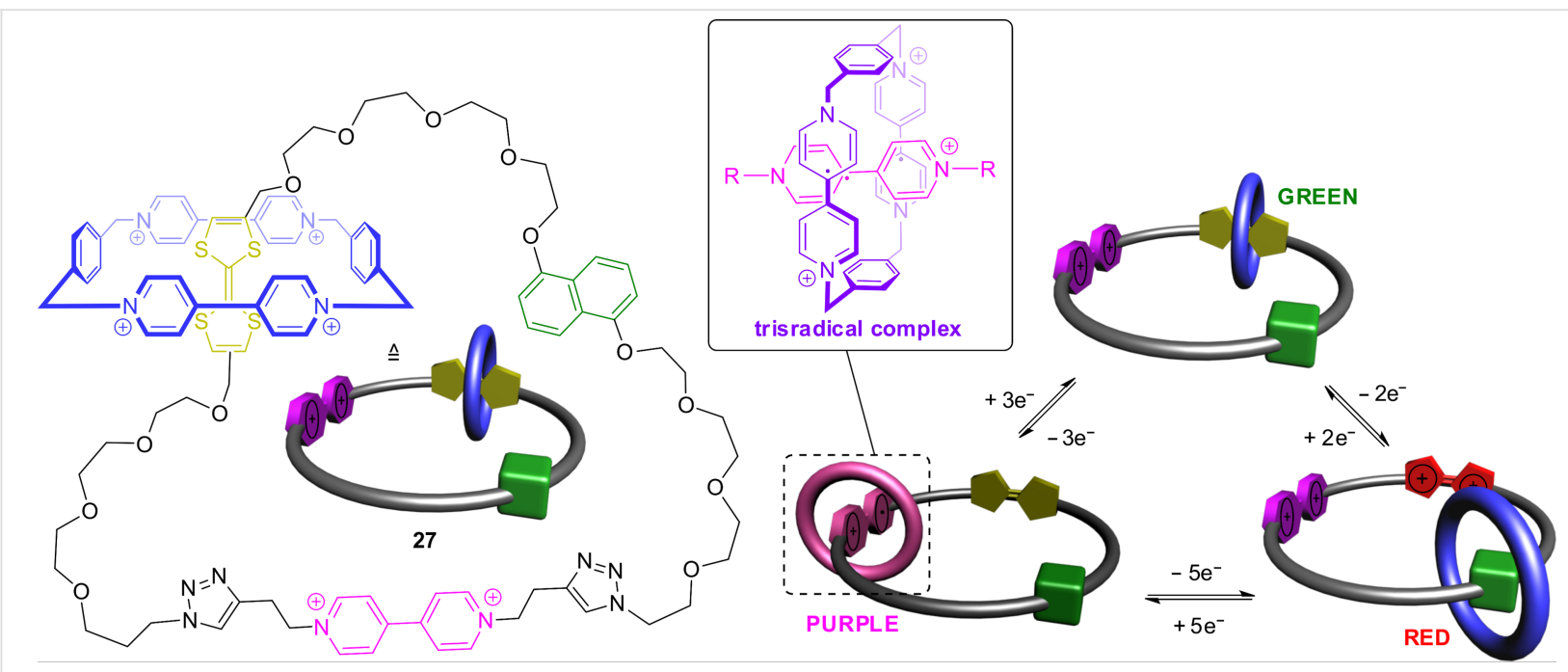

Figure 25: A tristable switch based on the redox-active [2]catenane 27 with three different stations. 


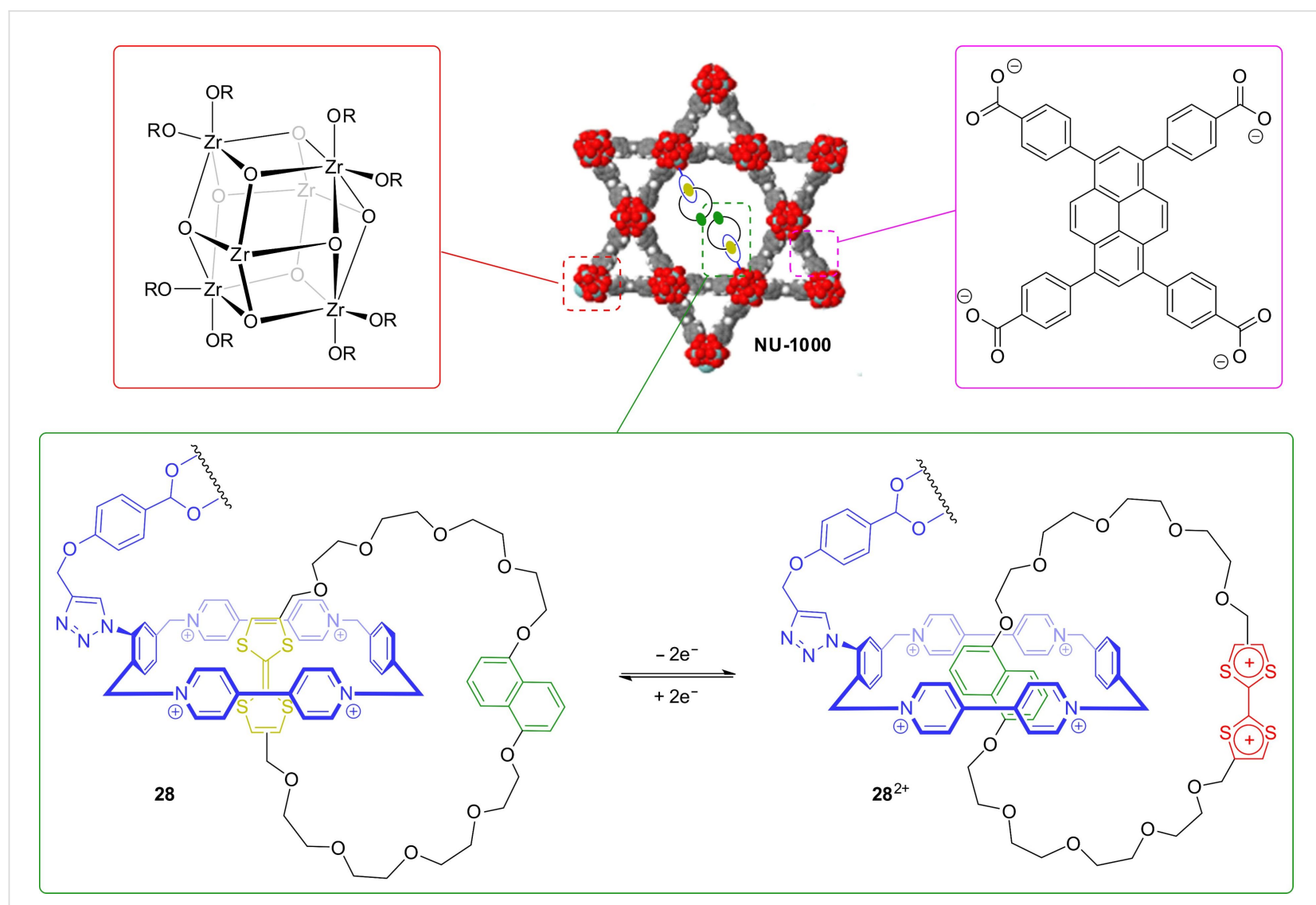

Figure 26: Structure of catenane-functionalized MOF NU-1000 [108] with structural representation of subcomponents. The TTF-based catenane 28 can be reversibly switched inside the MOF.

ordered catenanes of $8.8 \times 10^{19}$ units $\mathrm{cm}^{-3}$ in the MOF. Cyclic voltammetry in combination with chemical oxidation/reduction and powder-UV-vis-NIR spectroscopy showed the catenane to be reversibly switched inside the MOF.

\subsection{TTF Dimer interactions in catenanes}

Catenanes are ideally suited structures to enable the formation of TTF dimers, which need a confined molecular space to be stable at room temperature in solution. In 2010, the groups of Cooke and Stoddart described two [3]catenanes consisting of a cyclobis(paraquat-4,4'-biphenylene) and two TTF-based macrocycles (Figure 27a) [111]. Crystal structures of catenanes 29 and $\mathbf{3 0}$ showed that both TTF units are in the cavity of the central ring in the unswitched state. During the stepwise oxidation, both catenanes display characteristic spectroscopic features for stable mixed-valence $\left(\mathrm{TTF}_{2}\right)^{\bullet+}$ and radical-cation $\left(\mathrm{TTF}^{\bullet+}\right)_{2}$ dimers. The authors call the stabilizing environment of a [3]catenane a "molecular flask". However, whereas catenane 29 is directly oxidized from its radical-cation-dimer state $\left(\mathbf{2 9}^{2(\bullet+)}\right)$ to the fully oxidized $\mathbf{2 9}^{4+}$ state, the alkyne-based catenane shows a metastable disproportionation equilibrium between the $\mathbf{3 0}^{3+}$ state and the $\mathbf{3 0}^{2(\bullet+)} / \mathbf{3 0}^{4+}$ states. The authors explain the discrepancy by the additional binding energy of the dihydroxynaphthalene stations in $\mathbf{2 9}^{4+}$ to the cyclobis(paraquat4,4'-biphenylene) wheel. Therefore, the Coulomb repulsion and the subsequent expulsion of the $\mathrm{TTF}^{2+}$ units from the cavity of the central ring lead to a circumrotation of both outer wheels to a co-conformation in which the second binding stations are located in the cavity of the inner wheel.

In a series of similar self-assembled catenanes with a central metallo-supramolecular wheel (catenane $\mathbf{3 1}$ is shown exemplarily in Figure 27b), donor-acceptor interactions and hydrogen bonding generate a neutral TTF dimer that is surrounded by cofacially oriented bipyridinium units [112]. The intertwined structure is locked by formation of platinum(II)-pyridine coordination bonds. Interestingly, the doubly interlocked catenane features the topologic structure of a so-called Solomon link. It was shown that the oxidation of the Solomon link to the $\mathbf{3 1}^{\bullet+}$ state creates a stabilized mixed-valence dimer $\left(\mathrm{TTF}_{2}\right)^{\bullet+}$. However, in comparison to the structurally similar catenanes in this report, the radical-cation-dimer state $\left(\mathrm{TTF}^{\bullet+}\right)_{2}$ was only transiently stable. The authors suggest an effect of the constrained structural environment of the TTF units, which rationalizes the 

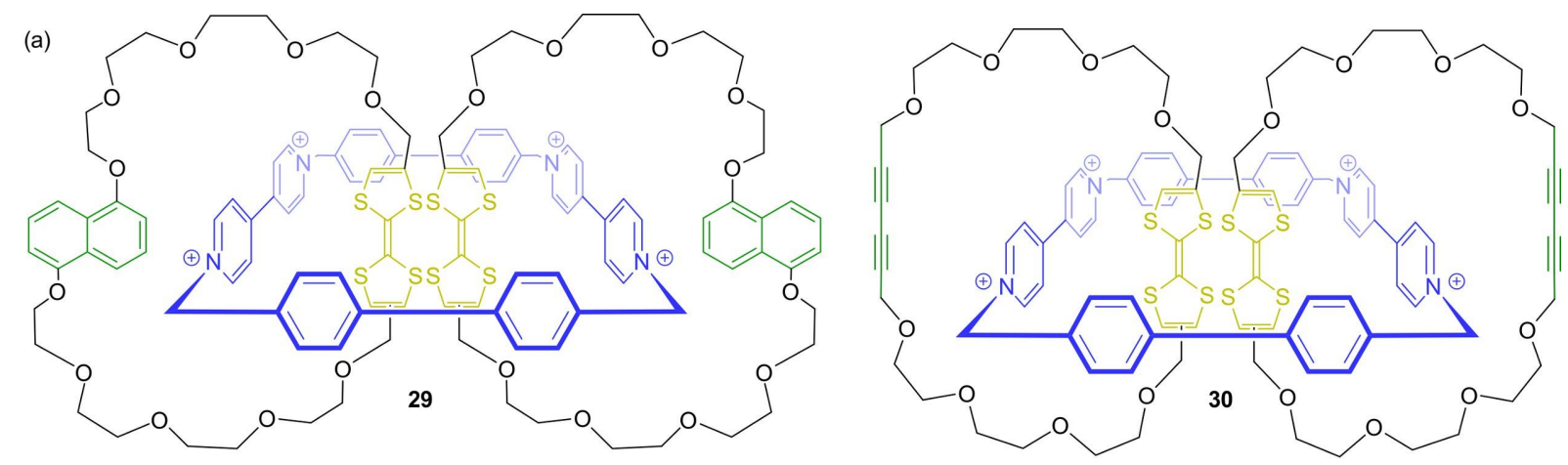

(b)
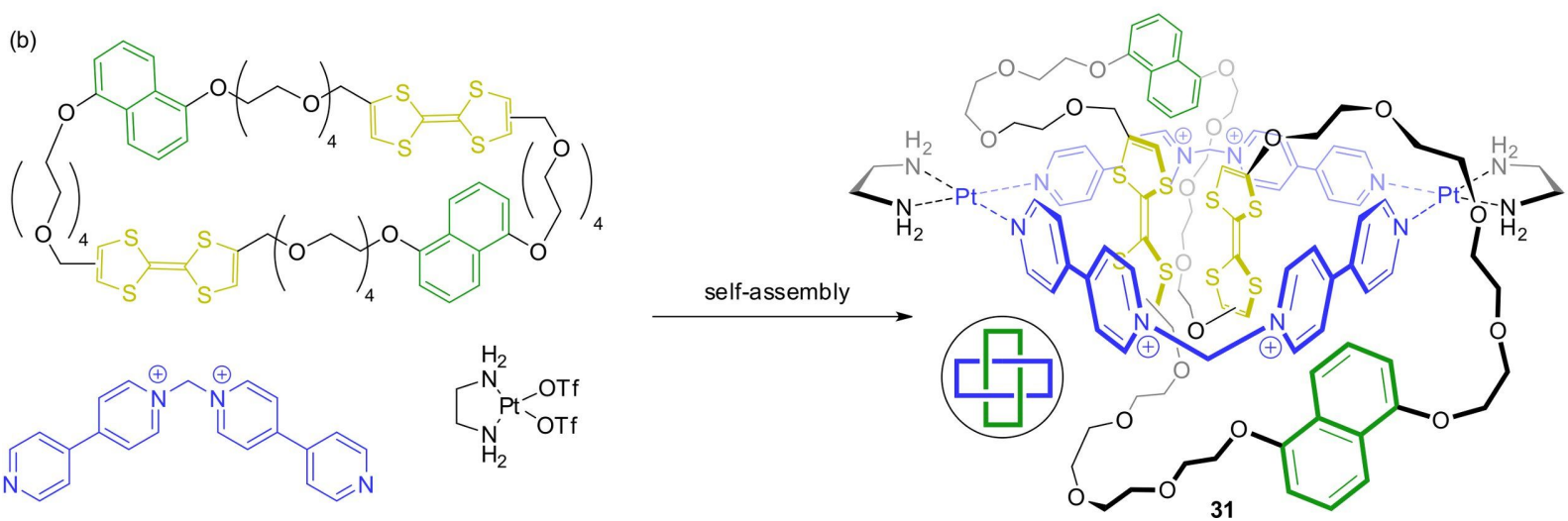

$\mathrm{N}_{\mathrm{H}_{2}}^{\mathrm{N}} \mathrm{Pt}^{\mathrm{H}}$-OTf

Figure 27: (a) [3]Catenanes $\mathbf{2 9}$ and $\mathbf{3 0}$ which can stabilize mixed-valence or radical-cation dimers of TTF. (b) Self-assembly synthesis of the molecular Solomon link 31 incorporating two TTF units.

reduced stability of the radical-cation dimer. Thus, also topological effects have to be considered for TTF dimer formation in redox-switchable MIMs.

\section{Conclusion}

The organosulfur compound TTF developed from a molecular switch with multiple electronic and material applications to one of the most widely used building blocks for the construction of stimuli-responsive MIMs and functional molecular devices. The development of straightforward organic reactions to implement TTFs in rotaxane or catenane structures lead to a variety of different construction motifs. Its high stability in three different oxidation states and the change of multiple properties during these successive oxidations are ideally suited to drive molecular motions in MIMs. Additionally, the optoelectronic and magnetic properties of TTF make it very easy to follow the stimuliinduced motion and the conformational changes accompanying it. TTF dimer interactions are relatively new yet offer an outstanding additional possibility to control molecular motion. In future, the already somewhat explored pathway to ordered arrays of TTF-based AMMs on surfaces or in (Sur)MOFs will enable macroscopic effects caused by concerted electrochemi- cal switching. Furthermore, the disadvantage of degradation of these organic molecules can be potentially overcome by incorporation into more robust materials. The initial dream that AMMs can be used one day to perform different tasks on the molecular level becomes slowly but steadily true. TTF and its derivatives will continue to contribute to this process.

\section{Acknowledgements}

We thank the Deutsche Forschungsgemeinschaft (CRC 765) for funding.

\section{ORCID ${ }^{\circledR}$ iDs}

Hendrik V. Schröder - https://orcid.org/0000-0002-6126-0055 Christoph A. Schalley - https://orcid.org/0000-0002-8634-3578

\section{References}

1. Boyer, P. D. Annu. Rev. Biochem. 1997, 66, 717-749. doi:10.1146/annurev.biochem.66.1.717

2. Kinbara, K.; Aida, T. Chem. Rev. 2005, 105, 1377-1400. doi:10.1021/cr030071r

3. Hirokawa, N.; Noda, Y.; Tanaka, Y.; Niwa, S. Nat. Rev. Mol. Cell Biol. 2009, 10, 682-696. doi:10.1038/nrm2774 
4. Balzani, V.; Credi, A.; Raymo, F. M.; Stoddart, J. F. Angew. Chem., Int. Ed. 2000, 39, 3348-3391. doi:10.1002/1521-3773(20001002)39:19<3348::AID-ANIE3348>3.0.C $\mathrm{O} ; 2-\mathrm{X}$

5. Coskun, A.; Banaszak, M.; Astumian, R. D.; Stoddart, J. F.; Grzybowski, B. A. Chem. Soc. Rev. 2012, 41, 19-30. doi:10.1039/C1CS15262A

6. Erbas-Cakmak, S.; Leigh, D. A.; McTernan, C. T.; Nussbaumer, A. L. Chem. Rev. 2015, 115, 10081-10206. doi:10.1021/acs.chemrev.5b00146

7. Sauvage, J.-P. Angew. Chem., Int. Ed. 2017, 56, 11080-11093. doi:10.1002/anie.201702992

8. Stoddart, J. F. Angew. Chem., Int. Ed. 2017, 56, 11094-11125. doi:10.1002/anie.201703216

9. Feringa, B. L. Angew. Chem., Int. Ed. 2017, 56, 11060-11078. doi:10.1002/anie.201702979

10. Xue, M.; Yang, Y.; Chi, X.; Yan, X.; Huang, F. Chem. Rev. 2015, 115, 7398-7501. doi:10.1021/cr5005869

11. Gil-Ramírez, G.; Leigh, D. A.; Stephens, A. J. Angew. Chem., Int. Ed. 2015, 54, 6110-6150. doi:10.1002/anie.201411619

12. Feringa, B. L. Acc. Chem. Res. 2001, 34, 504-513. doi:10.1021/ar0001721

13. Kassem, S.; van Leeuwen, T.; Lubbe, A. S.; Wilson, M. R.; Feringa, B. L.; Leigh, D. A. Chem. Soc. Rev. 2017, 46, 2592-2621. doi:10.1039/C7CS00245A

14. Ballardini, R.; Balzani, V.; Credi, A.; Gandolfi, M. T.; Venturi, M. Acc. Chem. Res. 2001, 34, 445-455. doi:10.1021/ar000170g

15. Jørgensen, T.; Hansen, T. K.; Becher, J. Chem. Soc. Rev. 1994, 23 , 41-51. doi:10.1039/CS9942300041

16. Simonsen, K. B.; Becher, J. Synlett 1997, 1211-1220. doi:10.1055/s-1997-1001

17. Nielsen, M. B.; Becher, J. Liebigs Ann./Recl. 1997, 2177-2187. doi:10.1002/jlac.199719971103

18. Nielsen, M. B.; Lomholt, C.; Becher, J. Chem. Soc. Rev. 2000, 29 153-164. doi:10.1039/a803992e

19. Bryce, M. R. J. Mater. Chem. 2000, 10, 589-598. doi:10.1039/a908385e

20. Canevet, D.; Sallé, M.; Zhang, G.; Zhang, D.; Zhu, D. Chem. Commun. 2009, 2245-2269. doi:10.1039/b818607n

21. Jana, A.; Ishida, M.; Park, J. S.; Bähring, S.; Jeppesen, J. O.; Sessler, J. L. Chem. Rev. 2017, 117, 2641-2710. doi:10.1021/acs.chemrev.6b00375

22. Deuchert, K.; Hünig, S. Angew. Chem., Int. Ed. Engl. 1978, 17, 875-886. doi:10.1002/anie.197808753

23. Wudl, F.; Smith, G. M.; Hufnagel, E. J. J. Chem. Soc. D 1970, 1453-1454. doi:10.1039/c29700001453

24. Devonport, W.; Blower, M. A.; Bryce, M. R.; Goldenberg, L. M. J. Org. Chem. 1997, 62, 885-887. doi:10.1021/jo960951o

25. Scott, B. A.; La Placa, S. J.; Torrance, J. B.; Silverman, B. D.; Welber, B. J. Am. Chem. Soc. 1977, 99, 6631-6639. doi:10.1021/ja00462a026

26. Ashton, P. R.; Balzani, V.; Becher, J.; Credi, A.; Fyfe, M. C. T.; Mattersteig, G.; Menzer, S.; Nielsen, M. B.; Raymo, F. M.; Stoddart, J. F.; Venturi, M.; Williams, D. J. J. Am. Chem. Soc. 1999, 121, 3951-3957. doi:10.1021/ja984341c

27. Bryce, M. R. Adv. Mater. 1999, 11, 11-23. doi:10.1002/(SICI)1521-4095(199901)11:1<11::AID-ADMA11>3.0.CO 2-3

28. Das, A.; Ghosh, S. Angew. Chem., Int. Ed. 2014, 53, 2038-2054. doi:10.1002/anie.201307756
29. Griffiths, K. E.; Stoddart, J. F. Pure Appl. Chem. 2008, 80, 485-506. doi:10.1351/pac200880030485

30. Andréasson, J.; Pischel, U. Chem. Soc. Rev. 2010, 39, 174-188. doi:10.1039/B820280J

31. Spanggaard, H.; Prehn, J.; Nielsen, M. B.; Levillain, E.; Allain, M.; Becher, J. J. Am. Chem. Soc. 2000, 122, 9486-9494. doi:10.1021/ja000537c

32. Khodorkovsky, V.; Shapiro, L.; Krief, P.; Shames, A.; Mabon, G.; Gorgues, A.; Giffard, M. Chem. Commun. 2001, 2736-2737. doi:10.1039/B104934H

33. Philp, D.; Slawin, A. M. Z.; Spencer, N.; Stoddart, J. F.; Williams, D. J. J. Chem. Soc., Chem. Commun. 1991, 1584-1586. doi:10.1039/c39910001584

34. Torrance, J. B.; Scott, B. A.; Welber, B.; Kaufman, F. B.; Seiden, P. E. Phys. Rev. B 1979, 19, 730-741. doi:10.1103/PhysRevB.19.730

35. Bozio, R.; Zanon, I.; Girlando, A.; Pecile, C. J. Chem. Phys. 1979, 71, 2282-2293. doi:10.1063/1.438564

36. Rosokha, S. V.; Kochi, J. K. J. Am. Chem. Soc. 2007, 129, 828-838. doi:10.1021/ja064166x

37. Christensen, C. A.; Becher, J.; Christensen, C. A.; Goldenberg, L. M.; Bryce, M. R. Chem. Commun. 1998, 509-510. doi:10.1039/a707504i

38. Hasegawa, M.; Nakamura, K.-i.; Tokunaga, S.; Baba, Y.; Shiba, R.; Shirahata, T.; Mazaki, Y.; Misaki, Y. Chem. - Eur. J. 2016, 22, 10090-10101. doi:10.1002/chem.201601785

39. Coffen, D. L. Tetrahedron Lett. 1970, 11, 2633-2636. doi:10.1016/S0040-4039(01)98299-1

40. Wudl, F.; Wobschall, D.; Hufnagel, E. J. J. Am. Chem. Soc. 1972, 94, 670-672. doi:10.1021/ja00757a079

41. Ferraris, J.; Cowan, D. O.; Walatka, V.; Perlstein, J. H. J. Am. Chem. Soc. 1973, 95, 948-949. doi:10.1021/ja00784a066

42. Kistenmacher, T. J.; Phillips, T. E.; Cowan, D. O. Acta Crystallogr., Sect. B: Struct. Crystallogr. Cryst. Chem. 1974, 30 , 763-768. doi:10.1107/S0567740874003669

43. Bendikov, M.; Wudl, F.; Perepichka, D. F. Chem. Rev. 2004, 104, 4891-4946. doi:10.1021/cr030666m

44. Wudl, F. Acc. Chem. Res. 2002, 17, 227-232. doi:10.1021/ar00102a005

45. Jérome, D.; Schulz, H. J. Adv. Phys. 2006, 31, 299-490. doi:10.1080/00018738200101398

46. Becher, J.; Lau, J.; Leriche, P.; Mørk, P.; Svenstrup, N. J. Chem. Soc., Chem. Commun. 1994, 2715-2716. doi:10.1039/C39940002715

47. Simonsen, K. B.; Svenstrup, N.; Lau, J.; Simonsen, O.; Mørk, P.; Kristensen, G. J.; Becher, J. Synthesis 1996, 1996, 407-418. doi:10.1055/s-1996-4216

48. Svenstrup, N.; Rasmussen, K. M.; Hansen, T. K.; Becher, J. Synthesis 1994, 809-812. doi:10.1055/s-1994-25580

49. Blanchard, P.; Sallé, M.; Duguay, G.; Jubault, M.; Gorgues, A. Tetrahedron Lett. 1992, 33, 2685-2688. doi:10.1016/S0040-4039(00)79057-5

50. Challenger, F.; Mason, E. A.; Holdsworth, E. C.; Emmott, R. J. Chem. Soc. 1953, 292-304. doi:10.1039/jr9530000292

51. Giffard, M.; Frère, P.; Gorgues, A.; Riou, A.; Roncali, J.; Toupet, L. J. Chem. Soc., Chem. Commun. 1993, 944-945. doi:10.1039/C39930000944

52. Li, Z.-T.; Stein, P. C.; Svenstrup, N.; Lund, K. H.; Becher, J. Angew. Chem., Int. Ed. Engl. 1995, 34, 2524-2528. doi:10.1002/anie.199525241 
53. Ballardini, R.; Balzani, V.; Becher, J.; Di Fabio, A.; Gandolfi, M. T.; Mattersteig, G.; Nielsen, M. B.; Raymo, F. M.; Rowan, S. J.; Stoddart, J. F.; White, A. J. P.; Williams, D. J. J. Org. Chem. 2000, 65, 4120-4126. doi:10.1021/jo0001941

54. Sallé, M.; Gorgues, A.; Jubault, M.; Boubekeur, K.; Batail, P. Tetrahedron 1992, 48, 3081-3090. doi:10.1016/S0040-4020(01)92250-1

55. Chen, W.; Cava, M. P.; Takassi, M. A.; Metzger, R. M. J. Am. Chem. Soc. 1988, 110, 7903-7904. doi:10.1021/ja00231a066

56. Jeppesen, J. O.; Perkins, J.; Becher, J.; Stoddart, J. F. Org. Lett. 2000, 2, 3547-3550. doi:10.1021/ol006387s

57. Jeppesen, J. O.; Becher, J. Eur. J. Org. Chem. 2003, 3245-3266. doi:10.1002/ejoc.200300078

58. Odell, B.; Reddington, M. V.; Slawin, A. M. Z.; Spencer, N.; Stoddart, J. F.; Williams, D. J. Angew. Chem., Int. Ed. Engl. 1988, 27, 1547-1550. doi:10.1002/anie.198815471

59. Anelli, P.-L.; Asakawa, M.; Ashton, P. R.; Bissell, R. A.; Clavier, G.; Górski, R.; Kaifer, A. E.; Langford, S. J.; Mattersteig, G.; Menzer, S.; Philp, D.; Slawin, A. M. Z.; Spencer, N.; Stoddart, J. F.; Tolley, M. S.; Williams, D. J. Chem. - Eur. J. 1997, 3, 1113-1135. doi:10.1002/chem.19970030719

60. Brøndsted Nielsen, M.; Hansen, J. G.; Becher, J. Eur. J. Org. Chem. 1999, 2807-2815. doi:10.1002/(SICI)1099-0690(199911)1999:11<2807::AID-EJOC2807 $>3.0 . \mathrm{CO} ; 2-\mathrm{N}$

61. Asakawa, M.; Ashton, P. R.; Balzani, V.; Credi, A.; Mattersteig, G.; Matthews, O. A.; Montalti, M.; Spencer, N.; Stoddart, J. F.; Venturi, M. Chem. - Eur. J. 1997, 3, 1992-1996. doi:10.1002/chem.19970031214

62. Asakawa, M.; Ashton, P. R.; Balzani, V.; Boyd, S. E.; Credi, A.; Mattersteig, G.; Menzer, S.; Montalti, M.; Raymo, F. M.; Ruffilli, C.; Stoddart, J. F.; Venturi, M.; Williams, D. J. Eur. J. Org. Chem. 1999, 985-994.

doi:10.1002/(SICI)1099-0690(199905)1999:5<985::AID-EJOC985>3.0 .CO;2-O

63. Kristensen, R.; Andersen, S. S.; Olsen, G.; Jeppesen, J. O. J. Org. Chem. 2017, 82, 1371-1379. doi:10.1021/acs.joc.6b02466

64. Nielsen, M. B.; Jeppesen, J. O.; Lau, J.; Lomholt, C.; Damgaard, D.; Jacobsen, J. P.; Becher, J.; Stoddart, J. F. J. Org. Chem. 2001, 66, 3559-3563. doi:10.1021/jo010173m

65. Schmidt, P. M.; Brown, R. S.; Luong, J. H. T. Chem. Eng. Sci. 1995, 50, 1867-1876. doi:10.1016/0009-2509(95)00046-8

66. Zhang, Y.-M.; Chen, Y.; Zhuang, R.-J.; Liu, Y. Supramol. Chem. 2011, 23, 372-378. doi:10.1080/10610278.2010.521828

67. Ziganshina, A. Y.; Ko, Y. H.; Jeon, W. S.; Kim, K. Chem. Commun. 2004, 806-807. doi:10.1039/B316651A

68. Jeon, W. S.; Kim, H.-J.; Lee, C.; Kim, K. Chem. Commun. 2002, 1828-1829. doi:10.1039/B202082C

69. Yoshizawa, M.; Kumazawa, K.; Fujita, M. J. Am. Chem. Soc. 2005, 127, 13456-13457. doi:10.1021/ja053508g

70. Schröder, H. V.; Wollschläger, J. M.; Schalley, C. A. Chem. Commun. 2017, 53, 9218-9221. doi:10.1039/C7CC05259F

71. Maksimov, M. O.; Pan, S. J.; James Link, A. Nat. Prod. Rep. 2012, 29, 996-1006. doi:10.1039/c2np20070h

72. Olson, M. A.; Botros, Y. Y.; Stoddart, J. F. Pure Appl. Chem. 2010, 82, 1569-1574. doi:10.1351/PAC-CON-10-02-09

73. Ashton, P. R.; Bissell, R. A.; Spencer, N.; Stoddart, J. F.; Tolley, M. S. Synlett 1992, 1992, 923-926. doi:10.1055/s-1992-21542

74. Li, Z.-T.; Stein, P. C.; Becher, J.; Jensen, D.; Mørk, P.; Svenstrup, N. Chem. - Eur. J. 1996, 2, 624-633. doi:10.1002/chem.19960020605
75. Jeppesen, J. O.; Perkins, J.; Becher, J.; Stoddart, J. F. Angew. Chem., Int. Ed. 2001, 40, 1216-1221. doi:10.1002/1521-3773(20010401)40:7<1216::AID-ANIE1216>3.0.CO ;2-W

76. Tseng, H.-R.; Vignon, S. A.; Stoddart, J. F. Angew. Chem., Int. Ed. 2003, 42, 1491-1495. doi:10.1002/anie.200250453

77. Deng, W. Q.; Muller, R. P.; Goddard, W. A., III. J. Am. Chem. Soc. 2004, 126, 13562-13563. doi:10.1021/ja036498x

78. Jang, Y. H.; Hwang, S.; Kim, Y.-H.; Jang, S. S.; Goddard, W. A., III. J. Am. Chem. Soc. 2004, 126, 12636-12645. doi:10.1021/ja0385437

79. Jang, Y. H.; Goddard, W. A., III. J. Phys. Chem. B 2006, 110, 7660-7665. doi:10.1021/jp055473c

80. Zhao, Y.-L.; Dichtel, W. R.; Trabolsi, A.; Saha, S.; Aprahamian, I.; Stoddart, J. F. J. Am. Chem. Soc. 2008, 130, 11294-11296. doi:10.1021/ja8036146

81. Olsen, J.-C.; Fahrenbach, A. C.; Trabolsi, A.; Friedman, D. C.; Dey, S. K.; Gothard, C. M.; Shveyd, A. K.; Gasa, T. B.; Spruell, J. M.; Olson, M. A.; Wang, C.; Jacquot de Rouville, H.-P.; Botros, Y. Y.; Stoddart, J. F. Org. Biomol. Chem. 2011, 9, 7126-7133. doi:10.1039/c1ob05913k

82. Schröder, H. V.; Sobottka, S.; Nößler, M.; Hupatz, H.; Gaedke, M.; Sarkar, B.; Schalley, C. A. Chem. Sci. 2017, 8, 6300-6306. doi:10.1039/C7SC02694C

83. Feringa, B. L.; Jager, W. F.; de Lange, B. Tetrahedron 1993, 49, 8267-8310. doi:10.1016/S0040-4020(01)81913-X

84. de Silva, A. P.; Dixon, I. M.; Gunaratne, H. Q. N.; Gunnlaugsson, T.; Maxwell, P. R. S.; Rice, T. E. J. Am. Chem. Soc. 1999, 121, 1393-1394. doi:10.1021/ja982909b

85. Avellini, T.; Li, H.; Coskun, A.; Barin, G.; Trabolsi, A.; Basuray, A. N.; Dey, S. K.; Credi, A.; Silvi, S.; Stoddart, J. F.; Venturi, M. Angew. Chem., Int. Ed. 2012, 51, 1611-1615. doi:10.1002/anie.201107618

86. Schröder, H. V.; Hupatz, H.; Achazi, A. J.; Sobottka, S.; Sarkar, B.; Paulus, B.; Schalley, C. A. Chem. - Eur. J. 2017, 23, 2960-2967. doi:10.1002/chem.201605710

87. Love, J. C.; Estroff, L. A.; Kriebel, J. K.; Nuzzo, R. G.; Whitesides, G. M. Chem. Rev. 2005, 105, 1103-1170. doi:10.1021/cr0300789

88. Balzani, V.; Credi, A.; Venturi, M. ChemPhysChem 2008, 9, 202-220. doi:10.1002/cphc.200700528

89. Ariga, K.; Mori, T.; Nakanishi, W.; Hill, J. P. Phys. Chem. Chem. Phys. 2017, 19, 23658-23676. doi:10.1039/C7CP02280H

90. Green, J. E.; Choi, J. W.; Boukai, A.; Bunimovich, Y.; Johnston-Halperin, E.; Delonno, E.; Luo, Y.; Sheriff, B. A.; Xu, K.; Shin, Y. S.; Tseng, H.-R.; Stoddart, J. F.; Heath, J. R. Nature 2007, 445, 414-417. doi:10.1038/nature05462

91. Luo, Y.; Collier, C. P.; Jeppesen, J. O.; Nielsen, K. A.; Delonno, E.; Ho, G.; Perkins, J.; Tseng, H.-R.; Yamamoto, T.; Stoddart, J. F.; Heath, J. R. ChemPhysChem 2002, 3, 519-525. doi:10.1002/1439-7641(20020617)3:6<519::AID-CPHC519>3.0.CO;22

92. Collier, C. P.; Mattersteig, G.; Wong, E. W.; Luo, Y.; Beverly, K.; Sampaio, J.; Raymo, F. M.; Stoddart, J. F.; Heath, J. R. Science 2000, 289, 1172-1175. doi:10.1126/science.289.5482.1172

93. Yu, H.; Luo, Y.; Beverly, K.; Stoddart, J. F.; Tseng, H.-R.; Heath, J. R. Angew. Chem., Int. Ed. 2003, 42, 5706-5711. doi:10.1002/anie.200352352

94. Tseng, H.-R.; Wu, D.; Fang, N. X.; Zhang, X.; Stoddart, J. F. ChemPhysChem 2004, 5, 111-116. doi:10.1002/cphc.200300992 
95. Feng, M.; Guo, X.; Lin, X.; He, X.; Ji, W.; Du, S.; Zhang, D.; Zhu, D.; Gao, H. J. Am. Chem. Soc. 2005, 127, 15338-15339. doi:10.1021/ja054836j

96. Huang, T. J.; Brough, B.; Ho, C.-M.; Liu, Y.; Flood, A. H.; Bonvallet, P. A.; Tseng, H.-R.; Stoddart, J. F.; Baller, M.; Magonov, S. Appl. Phys. Lett. 2004, 85, 5391-5393. doi:10.1063/1.1826222

97. Aprahamian, I.; Olsen, J.-C.; Trabolsi, A.; Stoddart, J. F. Chem. - Eur. J. 2008, 14, 3889-3895. doi:10.1002/chem.200800191

98. Schröder, H. V.; Mekic, A.; Hupatz, H.; Sobottka, S.; Witte, F.; Urner, L. H.; Gaedke, M.; Pagel, K.; Sarkar, B.; Paulus, B.; Schalley, C. A. submitted.

99. Barin, G.; Coskun, A.; Friedman, D. C.; Olson, M. A.; Colvin, M. T.; Carmielli, R.; Dey, S. K.; Bozdemir, O. A.; Wasielewski, M. R.; Stoddart, J. F. Chem. - Eur. J. 2011, 17, 213-222. doi:10.1002/chem.201002152

100.Jørgensen, T.; Becher, J.; Chambron, J.-C.; Sauvage, J.-P. Tetrahedron Lett. 1994, 35, 4339-4342. doi:10.1016/S0040-4039(00)73348-X

101.Dietrich-Buchecker, C. O.; Sauvage, J.-P.; Kintzinger, J. P. Tetrahedron Lett. 1983, 24, 5095-5098. doi:10.1016/S0040-4039(00)94050-4

102. Nielsen, M. B.; Li, Z.-T.; Becher, J. J. Mater. Chem. 1997, 7, 1175-1187. doi:10.1039/a700129k

103.Li, Z.-T.; Becher, J. Chem. Commun. 1996, 639-640. doi:10.1039/CC9960000639

104.Nielsen, M. B.; Thorup, N.; Becher, J. J. Chem. Soc., Perkin Trans. 1 1998, 1305-1308. doi:10.1039/a707854d

105.Asakawa, M.; Ashton, P. R.; Balzani, V.; Credi, A.; Hamers, C.; Mattersteig, G.; Montalti, M.; Shipway, A. N.; Spencer, N.; Stoddart, J. F.; Tolley, M. S.; Venturi, M.; White, A. J. P.; Williams, D. J. Angew. Chem., Int. Ed. 1998, 37, 333-337. doi:10.1002/(SICI)1521-3773(19980216)37:3<333::AID-ANIE333>3.0. CO;2-P

106.Sun, J.; Wu, Y.; Wang, Y.; Liu, Z.; Cheng, C.; Hartlieb, K. J.; Wasielewski, M. R.; Stoddart, J. F. J. Am. Chem. Soc. 2015, 137, 13484-13487. doi:10.1021/jacs.5b09274

107.Rowsell, J. L. C.; Yaghi, O. M. Microporous Mesoporous Mater. 2004, 73, 3-14. doi:10.1016/j.micromeso.2004.03.034

108.Chen, Q.; Sun, J.; Li, P.; Hod, I.; Moghadam, P. Z.; Kean, Z. S.; Snurr, R. Q.; Hupp, J. T.; Farha, O. K.; Stoddart, J. F. J. Am. Chem. Soc. 2016, 138, 14242-14245. doi:10.1021/jacs.6b09880

109. Mondloch, J. E.; Bury, W.; Fairen-Jimenez, D.; Kwon, S.; DeMarco, E. J.; Weston, M. H.; Sarjeant, A. A.; Nguyen, S. T.; Stair, P. C.; Snurr, R. Q.; Farha, O. K.; Hupp, J. T. J. Am. Chem. Soc. 2013, 135, 10294-10297. doi:10.1021/ja4050828

110.McGonigal, P. R.; Deria, P.; Hod, I.; Moghadam, P. Z.; Avestro, A.-J.; Horwitz, N. E.; Gibbs-Hall, I. C.; Blackburn, A. K.; Chen, D.; Botros, Y. Y.; Wasielewski, M. R.; Snurr, R. Q.; Hupp, J. T.; Farha, O. K.; Stoddart, J. F. Proc. Natl. Acad. Sci. U. S. A. 2015, 112 , 11161-11168. doi:10.1073/pnas.1514485112

111.Spruell, J. M.; Coskun, A.; Friedman, D. C.; Forgan, R. S.; Sarjeant, A. A.; Trabolsi, A.; Fahrenbach, A. C.; Barin, G.; Paxton, W. F.; Dey, S. K.; Olson, M. A.; Benítez, D.; Tkatchouk, E.; Colvin, M. T.; Carmielli, R.; Caldwell, S. T.; Rosair, G. M.; Hewage, S. G.; Duclairoir, F.; Seymour, J. L.; Slawin, A. M. Z.; Goddard, W. A., III; Wasielewski, M. R.; Cooke, G.; Stoddart, J. F. Nat. Chem. 2010, 2, 870-879. doi:10.1038/nchem.749
112.Frasconi, M.; Kikuchi, T.; Cao, D.; Wu, Y.; Liu, W.-G.; Dyar, S. M.; Barin, G.; Sarjeant, A. A.; Stern, C. L.; Carmieli, R.; Wang, C.; Wasielewski, M. R.; Goddard, W. A., III; Stoddart, J. F. J. Am. Chem. Soc. 2014, 136, 11011-11026. doi:10.1021/ja504662a

\section{License and Terms}

This is an Open Access article under the terms of the Creative Commons Attribution License (http://creativecommons.org/licenses/by/4.0). Please note that the reuse, redistribution and reproduction in particular requires that the authors and source are credited.

The license is subject to the Beilstein Journal of Organic Chemistry terms and conditions:

(https://www.beilstein-journals.org/bjoc)

The definitive version of this article is the electronic one which can be found at: doi:10.3762/bjoc. 14.190 